\title{
Pesticides and pesticide-related products in ambient air in Germany
}

\author{
Maren Kruse-Plaß ${ }^{1 *}$ (D) Frieder Hofmann² ${ }^{2}$ Werner Wosniok ${ }^{3}$, Ulrich Schlechtriemen ${ }^{4}$ and Niels Kohlschütter ${ }^{5}$
}

\begin{abstract}
Background: Tree bark measurements conducted between 2014 and 2017 in a biosphere reserve in Germany have indicated the presence of pesticides from conventional agriculture in ambient air. In the present study, we quantified pesticides and related substances in ambient air at 69 sites using passive air samplers and ventilation filter mats. It is, to our knowledge, so far the most comprehensive data set on pesticides and their related products in ambient air in Germany.

Results: Samples were collected in 2019 and analysed for over 500 substances. One hundred and nine (109) were detected, including 28 that are not approved for use in Germany. In each sampling site, we identified one to 36 substances, including locations such as national parks and forests. Here, the presence of pesticides is not expected, e.g., on the highest mountain top in the national park "Harz" (13 substances) and in the "Bavarian Forest" (six substances). Glyphosate was recorded in every sample. More than half of passive air samplers contained chlorothalonil, metolachlor, pendimethalin, terbuthylazine, prothioconazole-desthio, dimethenamid, prosulfocarb, flufenacet, tebuconazole, aclonifen, chlorflurenol, hexachlorobenzene (HCB), and $\gamma$-hexachlorocyclohexane $(\gamma-\mathrm{HCH})$. Filter mats also contained boscalid. The statistical analysis showed that landscape classification and agricultural intensity were the primary factors influencing the number of substances detected in ambient air. Location, such as protected areas or regions of organic farming, had only a small effect on the number of substances recorded. Medium- and long-range transport likely accounts for these findings. Extending the current sampling method will probably detect more pesticides than the data currently suggest.
\end{abstract}

Conclusions: Airborne pesticide mixtures are ubiquitous in Germany, which is particularly concerning for glyphosate, pendimethalin, and prosulfocarb. Deposition of these pesticides on organic products may disqualify them from the market, resulting in economic losses to farmers. Air concentrations of pesticides are a relevant issue and must be reduced.

Keywords: Pesticide, Passive air sampler, Glyphosate, Chlorothalonil, Metolachlor, Pendimethalin, Filter mat, Ventilation system

\section{Background}

The European Union Commission's proposal in May 2021 for a step-by-step reduction in pesticide application to $50 \%$ by 2030 as part of the farm-to-fork strategy is a result of the ongoing debate about the use of pesticides

\footnotetext{
*Correspondence: mkp@tieminfo.de

${ }^{1}$ TIEM Integrated Environmental Monitoring, 95615 Marktredwitz, Germany

Full list of author information is available at the end of the article
}

in general [1]. Pesticides are the largest group of synthetically produced substances released into the environment [2], designed to protect crops from pests and thus to secure agricultural production. Their use enables today's predominant industrial agriculture, but their high biological impact raises doubts about the health of humans, animals, and the environment. Therefore, pesticide application is heavily controlled. The testing of active substances is regulated in the approval regulation (EG) $1107 / 2009$ and national legislations such as the
Springer Open

(c) The Author(s) 2021. Open Access This article is licensed under a Creative Commons Attribution 4.0 International License, which permits use, sharing, adaptation, distribution and reproduction in any medium or format, as long as you give appropriate credit to the original author(s) and the source, provide a link to the Creative Commons licence, and indicate if changes were made. The images or other third party material in this article are included in the article's Creative Commons licence, unless indicated otherwise in a credit line to the material. If material is not included in the article's Creative Commons licence and your intended use is not permitted by statutory regulation or exceeds the permitted use, you will need to obtain permission directly from the copyright holder. To view a copy of this licence, visit http://creativecommons.org/licenses/by/4.0/. 
"Pflanzenschutzgesetz" valid in Germany. The National Action Plan of the Federal Government, which was drawn up from the framework directive on the sustainable use of pesticides (2009/128/EC), seeks extended goals and measures for improved protection of waterways and preservation of biological diversity [3].

While the environmental fate of pesticides in soil and their effects if released in water must be documented in the approval process, the regulating authorities concluded that sprayed pesticides do not drift far beyond their application site. Today, the data are largely generated by computer modelling [4]. In Germany, two metres for arable crops and five metres for spatial crops are regarded as sufficient to protect public spaces from pesticides [5]. Only for very volatile substances are these estimates validated by field measurements and result in altered regulations (Additional File 1) [6].

Airborne levels of pesticides are an ongoing issue. Organic farming in particular is affected [7], as auxiliaries such as synthetic chemical pesticides or fertilisers are not permitted. European Union Regulation No. 2018/848 [8] governs the process of organic agriculture and its inspection, from seeds or animal feed to the final product on the market. Ambient air pollution poses problems beyond the control of the organic economy.

An example is an incident in the largest continuous organic farming area in Europe (the biosphere reserve Schorfheide-Chorin, Germany). Here, organic grain fennel was not approved for marketing, because it contained high levels of pendimethalin. At that time, the State Agency for the Environment Brandenburg (Landesamt für Umwelt, Brandenburg) commissioned the first scientific analysis to record all relevant substances within the affected areas by means of air quality tree bark monitoring [9]. This study was expanded to include 47 tree bark samples from all areas of Germany in 2018. Air quality tree bark monitoring uses standardised samplers to collect the first millimetre of the outer bark, which consists of dead tissue, where a wide range of ambient air pollutants can accumulate over a timespan of 18-24 months. The samples were analysed for more than 500 pesticides and related substances, including glyphosate [9-11]. Pendimethalin and prosulfocarb were the most common pesticides found in the study, but persistent organic pollutants (POPs) such as dichlorodiphenyltrichloroethane (DDT) and $\gamma-\mathrm{HCH}$, the main compound in lindane, were also widespread. Glyphosate ranked fifth in detection frequency, demonstrating air transport of this pesticide.

Human exposure to glyphosate in Germany was previously measured in urine from 2000 test subjects. Levels did not differ significantly between individuals consuming only organically produced food and those consuming conventionally produced food, again suggesting airborne transport of this pesticide [12]. Since no data on pesticide occurrence in ambient air were available from official sources, a consortium of organic producers, suppliers, and non-governmental organisations was formed to enable research on the incidence of airborne pesticides and to extend the earlier work [9-11].

The commissioned study focusses on three questions:

\section{Are pesticides and related products detectable in ambient air in Germany?}

Samples were analysed for over 500 pesticides and their related products [13]. No other data are available for such a wide sampling range.

\section{Is transport of pesticides and related substances in the air beyond the spray drift range possible?}

To date, significant quantities of pesticides are not expected to travel far. This study included many sites, where no pesticides were expected, such as cities and protected areas (Additional Files 2, 3, and 4). The aim was to create an inventory of possible pesticide loads under a wide range of conditions. All sampling sites were, therefore, graded according to their distances from potential sources.

Collection of airborne pesticides is possible via active and passive sampling. In active sampling, a defined air volume is led through a cartridge comprising a glass fibre filter, a polyurethane foam (PUF) disk, an AmberLite resin core, and a second PUF disk [14]. This technique requires a local power supply and constant maintenance. Passive air samplers have been extensively validated in the Global Atmospheric Passive Sampling (GAPS) network $[15,16,17]$ but must be considered to yield only semi-quantitative results. The samplers enable the simultaneous collection of multiple substances, are relatively inexpensive, and their use is not technically demanding and can be accomplished by non-professional operators. To allow a wide range of sampling points to be analysed within the project's budget, the study focussed on passive air samplers exposed over 7 months.

A statistical analysis compared relevant location factors affecting the observed concentrations.

\section{Is pesticide identification limited to passive air samplers or can pesticides also be detected in other materials exposed to ambient air?}

Filter mats from ventilation systems, used to purify incoming outdoor air, were collected from 20 households and analysed. In Germany, an energy-saving regulation recommends a ventilation system for most new but also for existing buildings. Because of the airtight construction of buildings used today, controlling the entry of fresh air is essential. The filter mats were exposed over the 


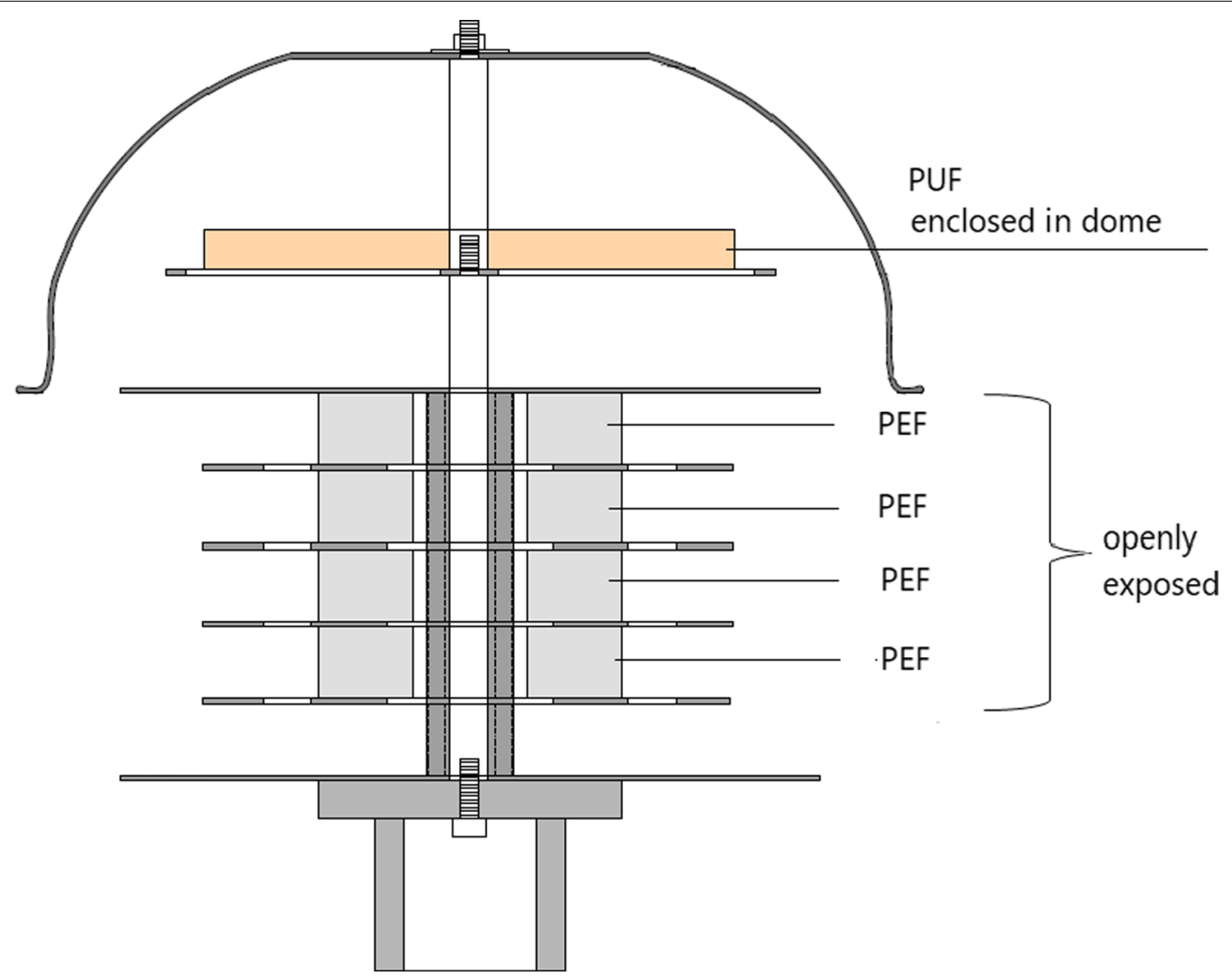

Fig. 1 Passive air sampler developed by TIEM technic

same timespan as the passive air samplers, thus enabling a comparison of collected substances and concentrations. The filter mats can qualitatively exhibit the presence of pesticides.

The results concentrate on the numbers of substances detected and their levels in samples from the site. Relating the observed concentrations to pesticide use and application, the physicochemical characteristics of the compound detected, and to other processes that may affect pesticide transport is a topic of further study.

\section{Materials and methods \\ Definition of terms}

A pesticide is the active substance of a plant-protection product, which can contain one or more pesticides plus formulation auxiliaries that ensure that pesticides are easy to handle and apply and have a long shelf life.

The list of substances to be analysed (Additional Files 5 and 6) includes those that are not pesticides in the strict sense: pesticide metabolites, safeners, synergists, auxiliary materials, and compounds unrelated to plant-protection products that are known to have adverse health effects or may occur unintentionally in agricultural products, such as polychlorinated biphenyls (PCBs) [39].
We identified four additional substances that may be of relevance: (hexachlorobenzene ( $\mathrm{HCB})$, anthraquinone, dichlorobenzophenone (DCBP-pp), and piperonyl butoxide (PBO); Additional File 7). All these substances are herein termed "pesticides and their related substances" unless a separate listing is required.

Our laboratory findings are concentrations of a substance in polyester filters (PEF) and PUF disks, expressed as nanograms per sample (ng/sample) for passive air samplers or micrograms per square metre $\left(\mu \mathrm{g} / \mathrm{m}^{2}\right)$ for ventilation filters. These concentrations must not be confused with the concentrations of a substance in ambient air. These were determined by model calculations only for a few data points later in this study.

\section{Passive air samplers}

For this project, specific passive air samplers were developed by TIEM technic. The collector (Fig. 1) uses a PUF disk, similar to the standard TE-200-PAS collectors used by the GAPS network. The PUF disks (diameter: $14 \mathrm{~cm}$; height: $1.35 \mathrm{~cm}$ ) were obtained from Tisch Environmental (Cleves, OH, USA) and have been validated for pesticide sampling [15-18] and confirmed in the work of 
Zhang et al. [19-21]. A Swedish program analysed 101 substances in PUF disks in 2017 [14].

However, no data were available on the efficacy of these passive air samplers in measuring glyphosate. Morshed et al. were unable to detect glyphosate in the otherwise effective PUF disk [22]. In a prior experiment [23], TIEM Environmental Monitoring established the PEF (diameter: $8 \mathrm{~cm}$; height: $2 \mathrm{~cm}$, with a round Sect. $3 \mathrm{~cm}$ in diameter in the middle; obtained from Freudenberg Filtration Technologies, Weinheim, Germany) as the most effective collection medium.

Therefore, the passive air sampler developed for this project combined the two sampling filters. An enclosed dome open to the outside air by a wide $(1.5 \mathrm{~cm})$ rim holds the PUF disk in a sheltered surrounding, while the PEF underneath is openly exposed (Fig. 1).

The polyurethane foam (PUF) disk captures volatile and semi-voltatile pesticides and a polyester filter (PEF) captures glyphosate, and aminomethylphosphonic acid.

The PUF disks were purified according to Pozo et al. [24]. The results obtained from the PUF disks used in the TIEM technic sampler did not differ significantly from the data obtained by TE-200-PAS collectors [25].

\section{Sample collection}

The installation of 49 samplers on site (Fig. 2) was carried out by TIEM Integrated Environmental Monitoring. Volunteers were trained in installing and replacing the samplers and provided with tools such as nitrile gloves, aluminium foil, tweezers, and storage and transport containers. The measurement period extended from the first 2 weeks in April to mid-November of 2019. PUF disks were replaced in mid-June, mid-August, and early to mid-November. TIEM Integrated Environmental Monitoring provided new PUF disks and volunteers stored the used disks in temperature-controlled boxes at $-18{ }^{\circ} \mathrm{C}$. At the end of the sampling period, all filters were shipped to TIEM Environmental Monitoring in temperaturecontrolled boxes with cooled thermal packs to avoid overheating and were subsequently forwarded to the analysing laboratory under the same conditions.

\section{Sample analysis}

The selection of the approximately 500 pesticides tested was based on the active ingredients listed for plant-based foods in the official multi-method (ASU L 00.00-115, 2018-10; QuEChERS) [26]. Some additional substances were added by the analysing laboratory because of consumer concerns. Chemical analysis was conducted by KWALIS (Fulda, Germany), registered with the German accreditation body (Deutsche Akkreditierungsstelle).

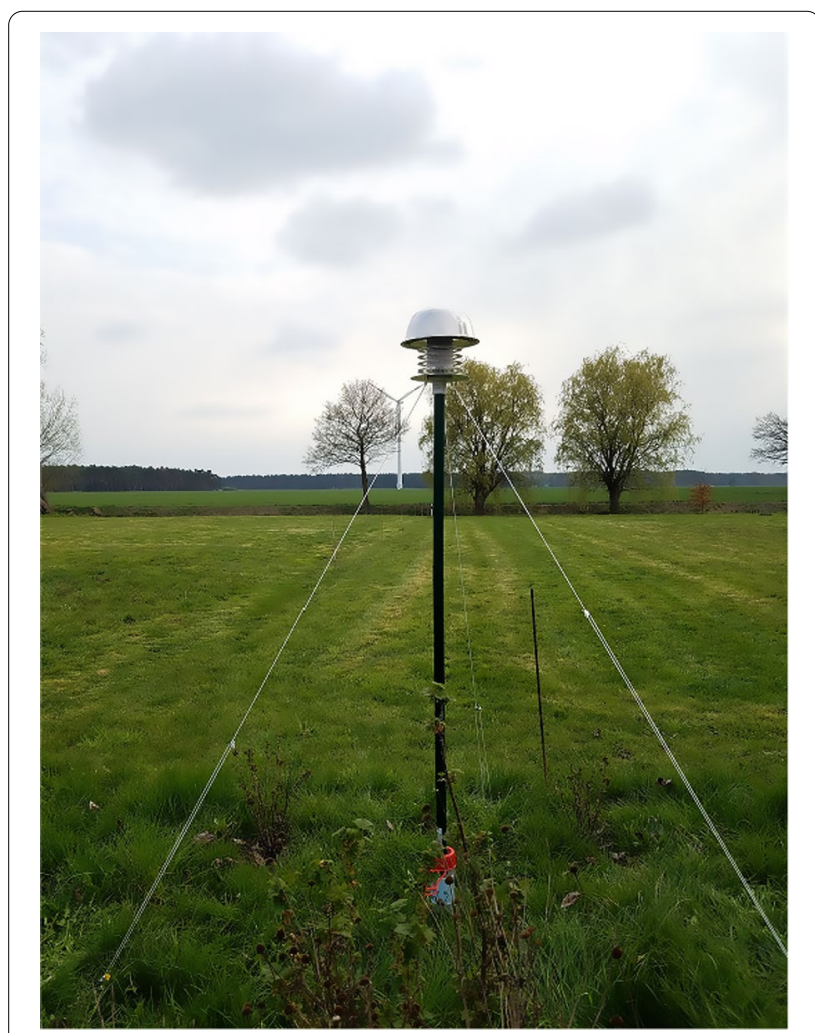

Fig. 2 Example of a passive air sampler in the field

\section{The PUF}

The extraction of the PUF was carried out with dichloromethane in a Soxhlet extractor [27]. The sample extracts were examined with gas chromatography (GC)-tandem mass spectrometry (MS/MS) (electron ionisation) and liquid chromatography (LC)-MS/MS (electrospray ionisation) in positive and negative mode. The injection volume was $1.5 \mu \mathrm{l}$ for the GC and $3 \mu \mathrm{l}$ for the LC.

In the extraction of the PUF, chlorpyrifos-ethyl D10 and triphenyl phosphate (200 ng each) were used as the recovery standards. DDT pp-D8 (100 ng), bentazon D6, atrazine-desethyl D7, HCH-alfa D6, cypermethrin D6, deltamethrin D6, HCB 13C6, and diazinon D10 (50 ng each) were added to the PUF material in the Soxhlet extractor.

The samples were extracted for $24 \mathrm{~h}$ using at least 16 extraction cycles. After cooling, n-butyl acetate was added as a keeper and the mixture was evaporated to approximately $20 \mathrm{ml}$. After concentrating the extract to $1 \mathrm{ml}$ under a stream of nitrogen, on the extract was analysed by LC-MS/MS and GC-MS/MS.

To check the recovery of the analytes in the Soxhlet extraction of the PUF with dichloromethane, recovery 
tests were carried out at the 100-ng level. Substances with recoveries of $60-140 \%$ are listed.

The analytes were identified by means of SRM with 2 productions with the correct ratio (deviation less than $30 \%$ compared to the reference) according to SANTE/11,813/2019 [28].

The analytical criteria for the identification refer to SANTE/11813/2019 [28] by LC-MS/MS or GC MS/ MS SRM with 2 productions within $30 \%$ correct ratio to reference.

\section{Procedural blanks and recovery standards}

To control possible contamination of the chemicals and devices, procedural blanks were included. In addition, pre-cleaned but unexposed PUF disks were examined to control possible blank values on the foams. To control the recovery during extraction and quantification, DDT-D8, triphenyl phosphate, and chlorpyrifos-ethyl D10 were used for GC-electron ionisation, triphenyl phosphate and chlorpyrifos-ethyl D10 were used for LC-electrospray ionisation in positive mode, and bentazone-D6 was used for LC-electrospray ionisation in negative mode as recovery standards. The recovery was in the range of 70-120\%.

\section{PEFs and filter mats for glyphosate}

Levels of glyphosate and aminomethylphosphonic acid (AMPA) in PEFs were validated according to SANTE/11813/2019 [28] by KWALIS separately [29]. The analysis was conducted by means of LC-MS/MS after extraction and derivatisation. Glyphosate and AMPA were extracted from the PEF materials with $0.125 \mathrm{~N}$ hydrochloric acid and then derivatised with fluorenylmethoxycarbonyl.

Quantification was conducted by adding the isotopelabelled standards ${ }^{13} \mathrm{C}_{2}{ }^{15} \mathrm{~N}$-glyphosate and ${ }^{13} \mathrm{C}^{15} \mathrm{~N}$-AMPA to the extraction solution. The identification of the analyte glyphosate -FMOC is carried out by the mass transitions 390>168 and 390>150; of the ILIS glyphosate ${ }^{13} \mathrm{C}_{2}{ }^{15} \mathrm{~N}$-FMOC by the mass transitions $393>171$ and $393>153$.

The AMPA analyte was identified via the mass transitions $332>110$ and $332>136$; of the ISTD AMPA ${ }^{13} \mathrm{C}^{15} \mathrm{~N}$ via the transitions $334>112$ and $334>138$.

The mass spectrometric analysis was carried out using a TSQ Vantage mass spectrometer (Thermo Fisher Scientific, Waltham, MA, USA).

The LC separation by means of an Accela ultrahighperformance liquid chromatographer (Thermo Fisher Scientific) was conducted on an RP 18AQ column $150 \times 2 \mathrm{~mm}$ (Reprosil PUR $120 \mathrm{C} 18-\mathrm{AQ}, 5 \mu \mathrm{m}$; Dr. Maisch HPLC GmbH; Ammerbuch, Germany) with a methanol-formic acid (0.01\%) gradient at $40{ }^{\circ} \mathrm{C}$.
Additional File 5 provides details the pesticides and related substances that were analysed and the analytical methods and limits of quantification (LQ).

\section{Filter mats from ventilation systems}

Passive air samplers are designed to minimise particulate contamination of the PUF disk [30] and, therefore, could not be used to assess pesticides on airborne particles. Instead, we collected filter mats from home ventilation systems, which are designed to remove dust and sometimes pollen from outside air entering buildings. Twenty volunteers submitted the filter mats in their homes for analysis.

\section{Sample collection}

All participants were asked to install a new filter mat on April 10, 2019 and ship it to TIEM Integrated Environmental Monitoring at the end of the measurement period (September 28 to October 8, 2019). The mats were forwarded to the analysing laboratory. All technical data and the characteristics of the sampling site were compiled in a protocol. Additional File 8 contains the specifications of the ventilation systems sampled. Unexposed filter mats were tested as blank samples.

\section{Sample analysis}

The extraction of the filter mats was performed according to QuEChERS (ASU L 00.00-115; [26]) in a 50-ml Falcon tube with an acetonitrile/water mixture with the addition of internal standards (chlorpyrifos-ethyl D10 and triphenyl phosphate, 200 ng each; bentazon D6, atrazine-desetyl D7, HCH-alfa D6, cypermethrin D6, and deltamethrin D6, 50 ng each) in an overhead shaker overnight for at least $12 \mathrm{~h}$. After adding the citrate salts and magnesium phosphate, the samples were centrifuged to separate the phases and purify the extract. The extract was measured using LC-MS/MS and GC-MS/MS without primary and secondary amine exchange material cleanup.

The sample extracts were analysed by GC-MS/MS (electron ionisation) and LC-MS/MS (electrospray ionisation) in positive and negative mode. The injection volume was $1.5 \mu \mathrm{l}$ for the GC and $3 \mu \mathrm{l}$ for the LC. The GC-MS/MS measurement was performed on a TSQ 9000 triple-stage qudrupole mass spectrometer (Thermo Scientific) with an advanced electron ionisation source. The GC separation was performed on a Trace 1310 GC on a 15 -m TG-5HT column (ID $0.25 \mathrm{~mm}$ with a film thickness of $0.25 \mu \mathrm{m}$; Thermo Fisher Scientific).

The LC-MS/MS measurement was performed on a TSQ Vantage triple-stage quadrupole mass spectrometer (Thermo Fisher Scientific) with electrospray ionisation in positive and negative mode. The LC separation was conducted on an Accela 1000 ultrahigh-performance 
liquid chromatographer (Thermo Fisher Scientific) with a $125 \times 2 \mathrm{~mm}$ RP18AQ column (Dr. Maisch) with an aqueous 5-mmol ammonium acetate/methanol gradient. Gradients were separated by a $125 \times 2 \mathrm{~mm}$ RP18AQ column (Dr. Maisch).

The analytes were identified by means of SRM with 2 productions with the correct ratio (deviation less than $30 \%$ compared to the reference) according to SANTE/11,813/2019 [28].

The analytical criteria for the identification refer to SANTE/11,813/2019 [28] by LC-MS/MS or GC MS/ MS SRM with 2 productions within $30 \%$ correct ratio to reference.

To control possible contamination of the chemicals and devices, procedural blanks were included. In addition, unexposed filter mats were analysed to control for possible blank values.

Additional File 6 details the pesticides and related substances analysed and the analytical methods and limits of quantification.

\section{Data files}

The limits of quantification of all substances detected in PUF disks and PEFs are given in Additional File 9, which includes the values recorded from passive air samplers. Seven values were below the limits of quantification but above the limits of detection (LD). Additional File 10 lists the findings for filter mats with limits of quantification and the concentrations measured. One value was below the limits of quantification but above the limits of detection.

\section{Selection of sampling sites and statistical analysis}

Volunteers willing to supervise a sampler or to donate a filter mat applied through a website. Sites of particular interest, such as national parks, were solicited as well. More than 250 sites were considered to obtain a reasonable nationwide coverage (Fig. 3) and to represent a wide range of sampling characteristics. Six characteristics presumed to be related to pesticide exposure were defined before the study commenced (Table 1 and Additional File 2) and were also used in the statistical analysis of the data, which dealt with the relationship between site features and pesticide concentrations [13]. The number of sites per category is given for all passive air sampler sites (Table 1, Additional File 3) and filter mat sites (Additional File 4). Two factors, agricultural intensity and risk of wind erosion, required some degree of estimation. Additional File 2 details the procedure used.

The location of the sampling sites is given with the reference site number 1 . Site number 1 may be used to match location with the data in Additional Files 9 and 10.
Sampling sites were selected to reflect a wide range of conditions: intensively farmed land, areas far from agricultural activity, forests, and cities. We included sites, where high exposure to pesticides could be expected (e.g., from intensive conventional farming) and sites, where no relevant exposure was anticipated (e.g., organic farming, protected areas, city centres).

The presence of currently used pesticides in ambient air is the consequence of spraying and airborne transport, sometimes by binding to particulates. The concentrations are likely to depend on the extent of pesticide use at the sites of origin, the distance from the application sites, meteorological conditions in the transport range, and geographical properties such as soil erosion. Land use may also be involved. This study, therefore, recorded site characteristics for inclusion in the analysis in combinations, as it is likely that these are not stand-alone factors. For example, northern Germany has large flat areas, where soil is prone to erosion and areas with intensive farming and wind conditions that favour medium- and long-range airborne transport. This means that statistical analyses of the relationship between site characteristics and pesticide concentrations must account for high-level interactions between factors. In view of the exploratory character of the analysis and the need to investigate high-level interactions, we used regression trees [31], i.e., a sequence of questions concerning the values of the explaining factors, ending in a prediction of the target quantity (pesticide concentration) that holds for all observations with the same answers in the question sequence. Such a sequence can easily be presented as a decision tree and is, therefore, simple to understand. The procedure selects the decision questions such that the final prediction of pesticide concentrations is as good as possible, where goodness is calculated as the variance of the difference between predicted and observed concentrations (the error variance). Observed concentrations enter the calculations as logarithms to make the variance a reasonable criterion. The importance of a factor is expressed as the coefficient of determination, the proportion of the maximal error variance (using only a constant as explanation) that is explained by the factor. The importance of the factor is in direct relation to the size of the proportion of the maximal error variance.

\section{Results}

Table 2 lists the concentrations of pesticides and related products measured in 49 passive air samplers and 20 filter mats, along with the number of pesticides detected over the study period per collection method. Eighty substances were detected in passive air samplers and 65 substances in filter mats. Glyphosate and AMPA were found with both methods. The number of 


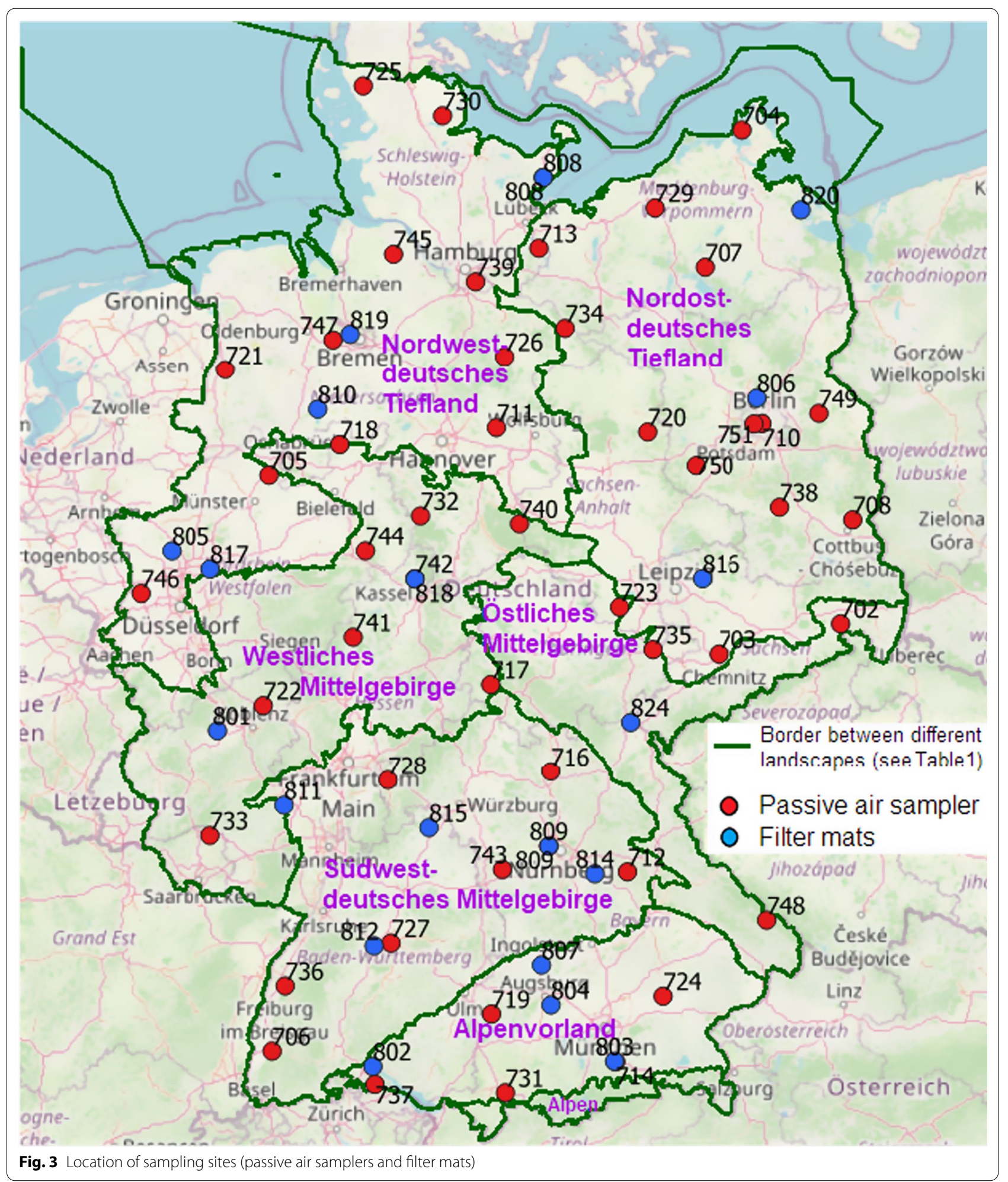


Table 1 Evaluation criteria for sampling sites

\begin{tabular}{|c|c|c|c|}
\hline Factor & & $\begin{array}{l}\text { Code in } \\
\text { Regression tree }\end{array}$ & $\begin{array}{l}\text { Number of } \\
\text { cases passive air } \\
\text { sampler }\end{array}$ \\
\hline Landscape classification & Alpenvorland (AVL) & a & 5 \\
\hline in regression tree: & Nordostdeutsches Tiefland (NOTL) & $\mathrm{b}$ & 13 \\
\hline \multirow[t]{4}{*}{ "Naturraum " } & Nordwestdeutsches Tiefland (NWTL) & c & 11 \\
\hline & Östliches Mittelgebirge (OMG) & $d$ & 4 \\
\hline & $\begin{array}{l}\text { Südwestdeutsches Mittelgebirge / Stufenland } \\
\text { (SWMGS) }\end{array}$ & e & 8 \\
\hline & Westliches Mittelgebirge (WMG) & $f$ & 8 \\
\hline Biogeographical region & Atlantical & a & 11 \\
\hline "BioGeo " & Continental & $b$ & 38 \\
\hline Risk of wind erosion & $0.0-1.0$ & a & 28 \\
\hline \multirow[t]{3}{*}{ "Erosion3 " } & $1.5-2.0$ & $\mathrm{~b}$ & 7 \\
\hline & $2.5-3.0$ & c & 12 \\
\hline & $3.5-5.0$ & $d$ & 2 \\
\hline Protected area & No & a & \\
\hline "SchutzGebJN " & Yes & $b$ & \\
\hline Agricultural intensity & Low (Ratio 0-20\%) & a & 10 \\
\hline "LwIntK" & Medium (Ratio 20-50\%) & $\mathrm{b}$ & 13 \\
\hline $\begin{array}{l}\text { Percentage of arable farming in a } 4 \mathrm{~km}^{2} \text { area } \\
\text { around the sampling site }\end{array}$ & High (Ratio > 50\%) & c & 26 \\
\hline Distance to the nearest possible source & Close range: a few $\mathrm{m}$ to $100 \mathrm{~m}$ & a & 16 \\
\hline \multirow[t]{2}{*}{ "DistanzE " } & Middle range: 100-1000 m & $\mathrm{b}$ & 21 \\
\hline & Far distance: over $1000 \mathrm{~m}$ & c & 12 \\
\hline Organic production & No & a & 39 \\
\hline "BioJN " & Yes (including 2 National Parks) & $\mathrm{b}$ & 10 \\
\hline
\end{tabular}

Table 2 Pesticides and related substances detected in passive air samplers and filter mats

\begin{tabular}{|c|c|c|}
\hline Parameter & Passive air samplers & Filter mats \\
\hline Number of sampling locations & 49 & 20 \\
\hline Number of substances detected & 78 & 63 \\
\hline $\begin{array}{l}\text { Additionally } \\
\text { Glyphosate and AMPA }\end{array}$ & Both detected & Both detected \\
\hline Number of substances detected per sampling site & $6-33$ & $1-36$ \\
\hline Median & 19 & 9 \\
\hline Number of substances detected by only one collection method & 44 & 29 \\
\hline Number of substances detected that are not approved for use in Germany & $21^{\mathrm{a}}$ & 11 \\
\hline PCBs (unintentionally products) & 5 & \\
\hline Metabolites & 4 & 6 \\
\hline Number of substances detected in both collection methods & 36 & \\
\hline $\begin{array}{l}\text { Number of substances detected in passive air samplers and filter mats } \\
\text { (listed in Additional File 11) }\end{array}$ & 109 & \\
\hline Number of substances detected that are not approved for use in Germany & $28^{\mathrm{a}}$ & \\
\hline Substances detected that are banned under the Stockholm Convention & \multicolumn{2}{|c|}{14 (including five PCBs and five forms of DDT compounds) } \\
\hline Details & Additional File 9 & Additional File 10 \\
\hline
\end{tabular}

${ }^{\text {a }}$ Including endosulfan sulfate and derivatives of DDT, which are metabolites of persistent organic pollutants (POPs) listed under the Stockholm Convention 
Table 3 Substances detected in passive air samplers at more than one third of sampling sites

\begin{tabular}{|c|c|c|c|c|c|c|c|}
\hline Substance & Active compound type & $\begin{array}{l}\text { Detection } \\
\text { frequency } \\
(\mathrm{N}=49)\end{array}$ & $\begin{array}{l}\text { Maximum } \\
\text { (ng/ } \\
\text { sample) }\end{array}$ & $\begin{array}{l}\text { Minimum } \\
\text { (ng/ } \\
\text { sample) }\end{array}$ & $\begin{array}{l}\text { Total } \\
\text { quantity } \\
\text { in all } 49 \\
\text { samples } \\
\text { (ng) }\end{array}$ & $\begin{array}{l}\text { Median } \\
\text { (ng/ } \\
\text { sample) }\end{array}$ & $\begin{array}{l}\text { Approved } \\
\text { for use in } \\
\text { Germany }\end{array}$ \\
\hline Glyphosate & Herbicide & $49 / 49$ & 3176.8 & 20.3 & $13,122.3$ & 98.4 & Yes \\
\hline Chlorothalonil & Fungicide & $47 / 49$ & 1866.2 & 0 & $23,247.3$ & 272.5 & Yes \\
\hline Metolachlor & Herbicide & $45 / 49$ & 1273.3 & 0 & 8075.8 & 58.1 & Yes \\
\hline Pendimethalin & Herbicide & $44 / 49$ & 3916.8 & 0 & $21,942.0$ & 145.5 & Yes \\
\hline Terbuthylazine & Herbicide & $44 / 49$ & 905.9 & 0 & 6061.2 & 77.3 & Yes \\
\hline Prothioconazole-desthio & Metabolite & $42 / 49$ & 329.0 & 0 & 2797.2 & 35.0 & Not regulated \\
\hline Dimethenamid & Herbicide & $40 / 49$ & 1556.6 & 0 & 4960.8 & 37.6 & Yes \\
\hline Prosulfocarb & Herbicide & $40 / 49$ & 2505.3 & 0 & $11,872.9$ & 90.7 & Yes \\
\hline Aminomethylphosphonic acid & Metabolite & $40 / 49$ & 402.6 & 0 & 2548.4 & 25.1 & Not regulated \\
\hline Flufenacet & Herbicide & $35 / 49$ & 204.6 & 0 & 1872.9 & 20.0 & Yes \\
\hline Tebuconazole & Fungicide & $32 / 49$ & 114.7 & 0 & 984.3 & 13.9 & Yes \\
\hline Aclonifen & Herbicide & $27 / 49$ & 479.7 & 0 & 1816.3 & 12.2 & Yes \\
\hline Chlorflurenol & Growth regulator & $27 / 49$ & 229.1 & 0 & 2687.7 & 53.9 & No \\
\hline Hexachlorobenzene & Fungicide & $27 / 49$ & 46.3 & 0 & 805.5 & 10.8 & No \\
\hline Y-hexachlorocyclohexane & Insecticide, Repellent & $26 / 49$ & 267.4 & 0 & 1431.0 & 16.5 & No \\
\hline $\begin{array}{l}\text { 2-Methyl-4-chlorophenoxyacetic } \\
\text { acid }\end{array}$ & Herbicide & $22 / 49$ & 90.8 & 0 & 519.6 & 0.0 & Yes \\
\hline Epoxiconazole & Fungicide & $18 / 49$ & 81.3 & 0 & 433.0 & 0.0 & Yes \\
\hline Folpet & Fungicide & $17 / 49$ & 7613.8 & 0 & 8958.6 & 0.0 & Yes \\
\hline
\end{tabular}

substances per site ranged from six to 33 in passive air samplers and one to 36 in filter mats. Additional File 11 lists all 109 substances detected, 28 of which are no longer approved for use in Germany.

Thirty-six substances were measured in both passive air samplers and filter mats, while 44 substances were detected exclusively in passive air samplers and 29 were detected only in filter mats.

Table 3 lists the substances that were detected in passive air samplers at more than one third of sites. Table 4 lists the substances that were detected in filter mats in at least one third of the sampling sites. As the quality of the filter materials was variable, the data are used only qualitatively.

In addition to glyphosate and AMPA, we found tebuconazole, epoxiconazole, and folpet in both passive air samplers and filter mats. In passive air samplers, we commonly found high concentrations of prothioconazol-desthio, dimethenamid, and prosulfocarb. The most frequently detected substances were herbicides (nine out of 18), while fungicides dominated in filter mats (nine out of 12).

Figure 4 shows the 18 most abundant substances in the PUF samples. The maximum value for a single substance was measured for folpet (7613.8 ng/sample) at one location, and this high value may indicate proximity to a site of application.

Values for pesticides and related products detected in more than one third of sampling sites on a logarithmic scale. Blue bars represent the detection frequency

Table 4 Substances detected in filter mats in at least one third of the sampling sites

\begin{tabular}{|c|c|c|c|}
\hline Substance & $\begin{array}{l}\text { Active } \\
\text { compound } \\
\text { type }\end{array}$ & $\begin{array}{l}\text { Detection } \\
\text { frequency } \\
(\mathrm{N}=20)\end{array}$ & $\begin{array}{l}\text { Approved for use } \\
\text { in Germany }\end{array}$ \\
\hline Glyphosate & Herbicide & $20 / 20$ & Yes \\
\hline $\begin{array}{l}\text { Aminomethyl- } \\
\text { phosphonic acid }\end{array}$ & Metabolite & $17 / 20$ & Not regulated \\
\hline Boscalid & Fungicide & $13 / 20$ & Yes \\
\hline Anthraquinone ${ }^{a}$ & Repellent & $9 / 20$ & No \\
\hline Fenpropidin & Fungicide & $9 / 20$ & Yes \\
\hline Azoxystrobin & Fungicide & $8 / 20$ & Yes \\
\hline Tebuconazole & Fungicide & $8 / 20$ & Yes \\
\hline Ametoctradin & Fungicide & $7 / 20$ & Yes \\
\hline Dichlorane & Fungicide & $7 / 20$ & No \\
\hline Epoxiconazole & Fungicide & $7 / 20$ & Yes \\
\hline Folpet & Fungicide & $7 / 20$ & Yes \\
\hline Mandipropamid & Fungicide & $7 / 20$ & Yes \\
\hline
\end{tabular}

a Substance attributable to agricultural as well as non-agricultural sources 


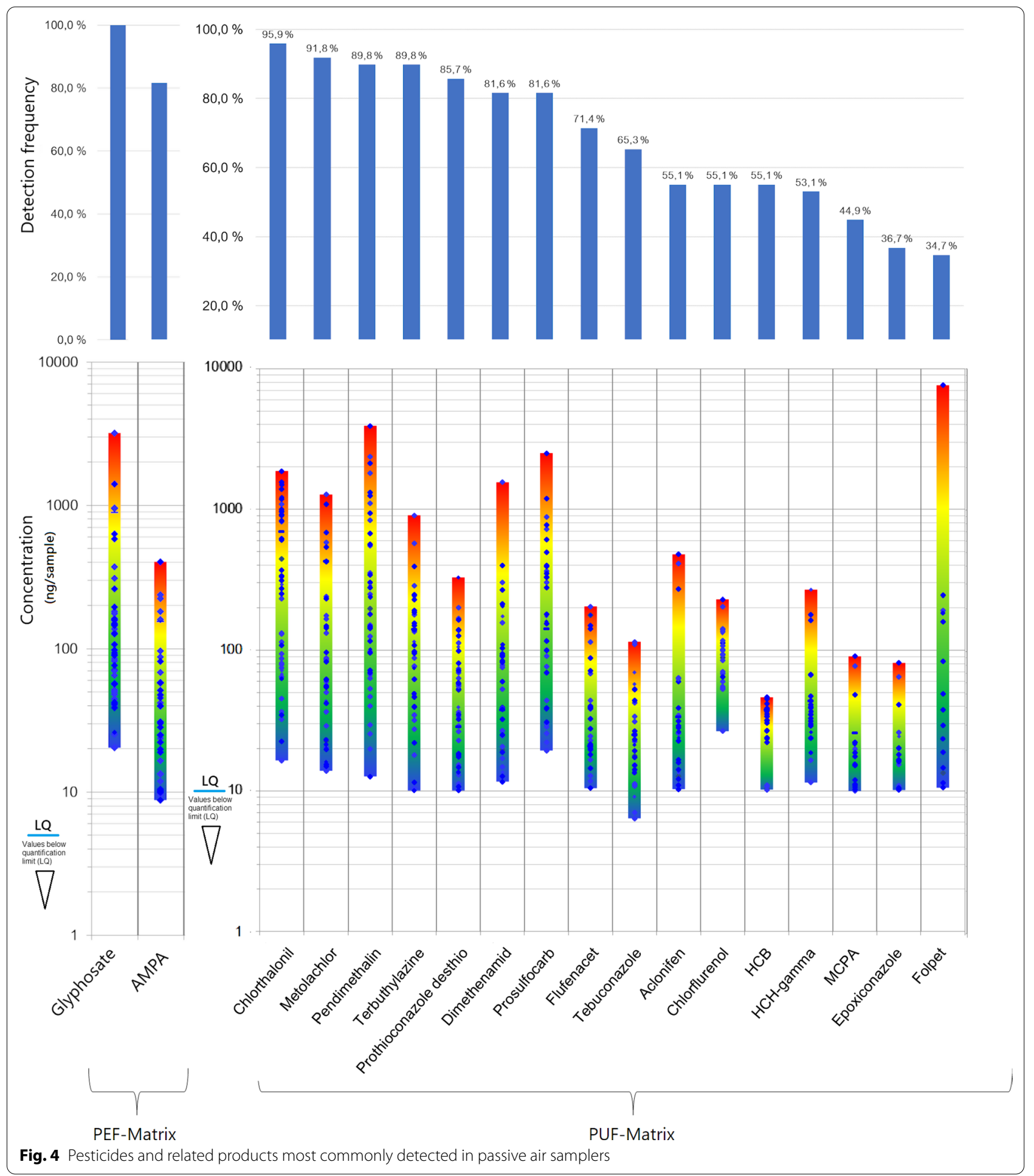

relative to all sites sampled. The coloured bars indicate the spread of the values. Blue diamonds represent individual values. See also Additional File 9. AMPA, aminomethylphosphonic acid; $\mathrm{HCB}$, hexachlorobenzene;
$\mathrm{HCH}$, hexachlorocyclohexane; MCPA, 2-methyl-4-chlorophenoxyacetic acid. An LQ above $10 \mathrm{ng}$ is only registerd for Chlorfurenol (20 ng). 


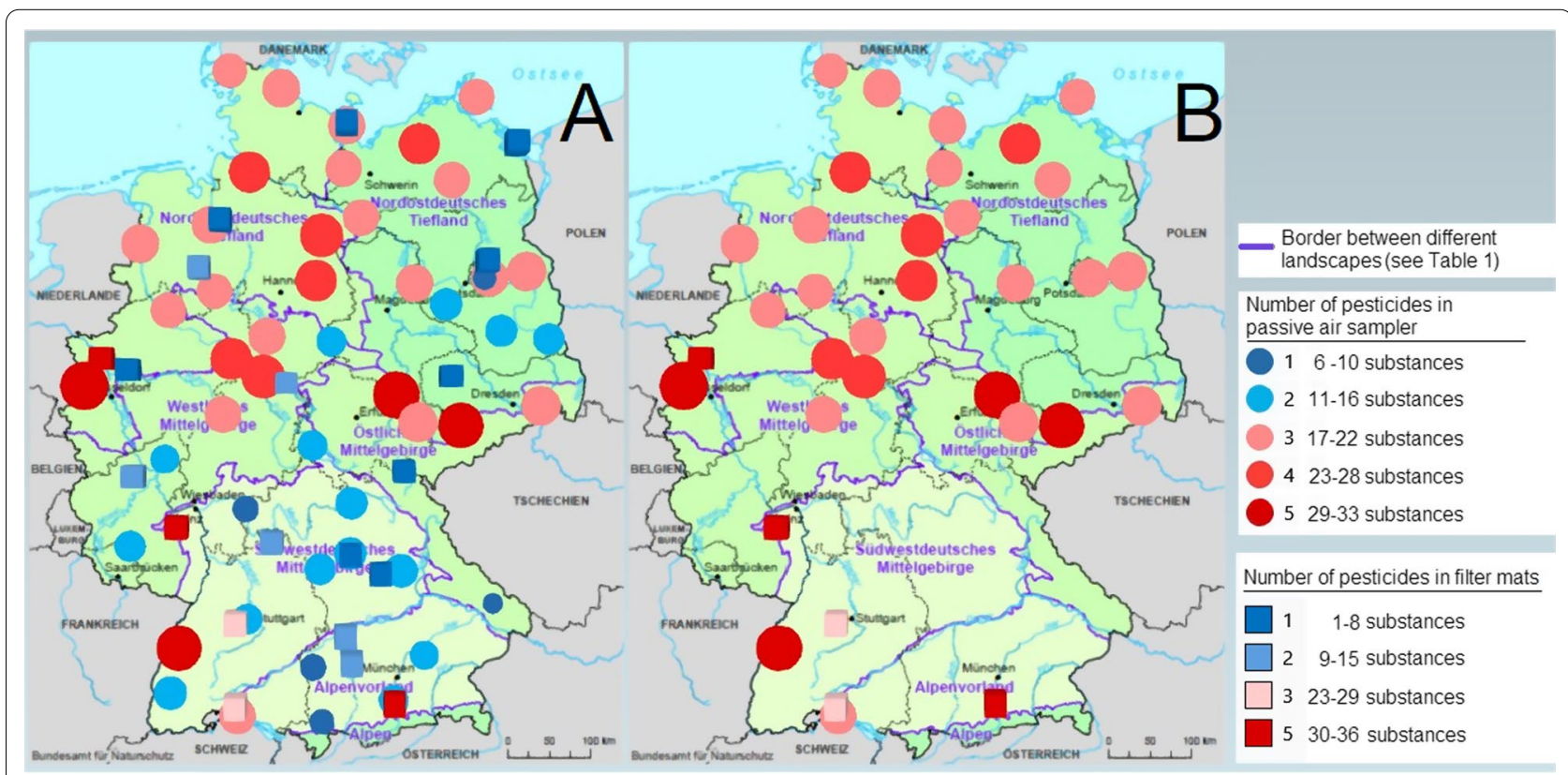

Fig. 5 Number of substances detected at sampling sites. A All sampling sites. B Sampling sites, where more than 16 substances were detected in passive air samplers and more than 22 substances were detected in filter mats

Table 5 Statistical analysis for the total number of substances detected per site in passive air samplers

\begin{tabular}{lcl}
\hline Statistical Parameter & Coefficient of determination & $\begin{array}{l}\text { Contribution of statistical parameter } \\
\text { to total coefficient of determination } \\
\text { (\%) }\end{array}$ \\
\hline $\begin{array}{l}\text { Landscape classification } \\
\text { Biogeographical region }\end{array}$ & 30.1 & 53.9 \\
Risk of wind erosion & & \\
Protected areas & 5.9 & 10.6 \\
Agricultural intensity & 13.5 & 24.2 \\
Distance to the nearest possible source & 6.3 & 11.3 \\
Organic production & & \\
Total explained proportion of variance (\%) & 55.8 & 100 \\
\hline
\end{tabular}

\section{Spatial distribution of pesticides and related products}

Figure 5A shows the pesticide burden in the sampling sites as the number of substances detected in the samples and Fig. 5B shows only the sites with the highest number of pesticides and related products.

Many of the sites with a high pesticide burden were in the northern regions of Germany, where intensive agriculture is possible. In the mountainous southern regions, high values may indicate vineyards and fruit crops. A considerable number of substances per site was also detected in unexpected places such as national parks in the Harz (13 substances) and Bavarian Forest (six substances) air samplers and six substances respectively (Additional File 12).

\section{Results of the statistical analysis}

For passive samplers, the statistical analysis of the number of pesticides and related substances identified landscape classification as the most influential factor in the overall observed variance (Table 5). However, agricultural activity in the immediate surroundings was the primary influence in the regression tree (Additional File 13; Table 5). Medium or high agricultural activity, noted for 39 sites, increased the overall median number of pesticides per site from 16.8 to 18.1 . $^{1}$ The effect, which adds $6.3 \%$ to the total explained variance, is relatively small.

\footnotetext{
${ }^{1}$ The sample median in the regression analysis is not identical to the descriptive statistical median.
} 


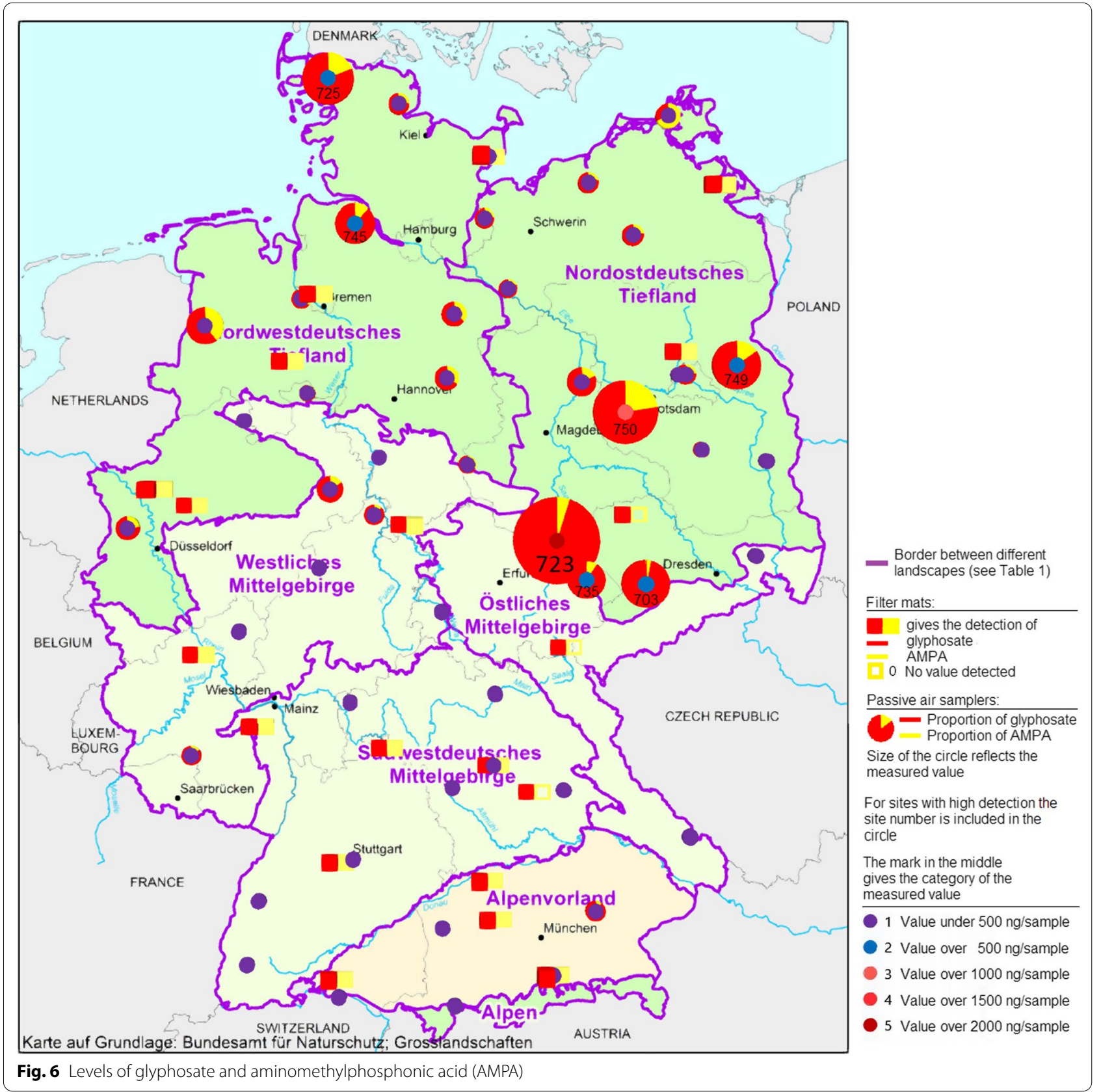

Depending further on the landscape, the median number of pesticides increased to 23.8 , with landscape contributing a total of $30.1 \%$ to the total explained variation. Landscape classification in general was the most important factor in the number of pesticides and related products we detected (Table 5), but its effects formed a complex pattern (Additional File 13). Both factors, agricultural activity and landscape classification, were not completely independent. Sites in protected areas (contribution to overall variance: $5.9 \%$ ) reduced the number of substances detected to 15.8 in two of the landscape classes, Nordostdeutsches Tiefland and Westliches Mittelgebirge. However, in the other four landscape classes, the median increased to 23.8. Consequently, protected areas appear to offer little to no shelter against a large number of airborne pesticides and their related substances. Biogeographical regions, areas with risks of wind erosion, and areas with biological production did not differ from other areas in the number of substances detected.

Additional File 13 shows the results as a regression tree. 


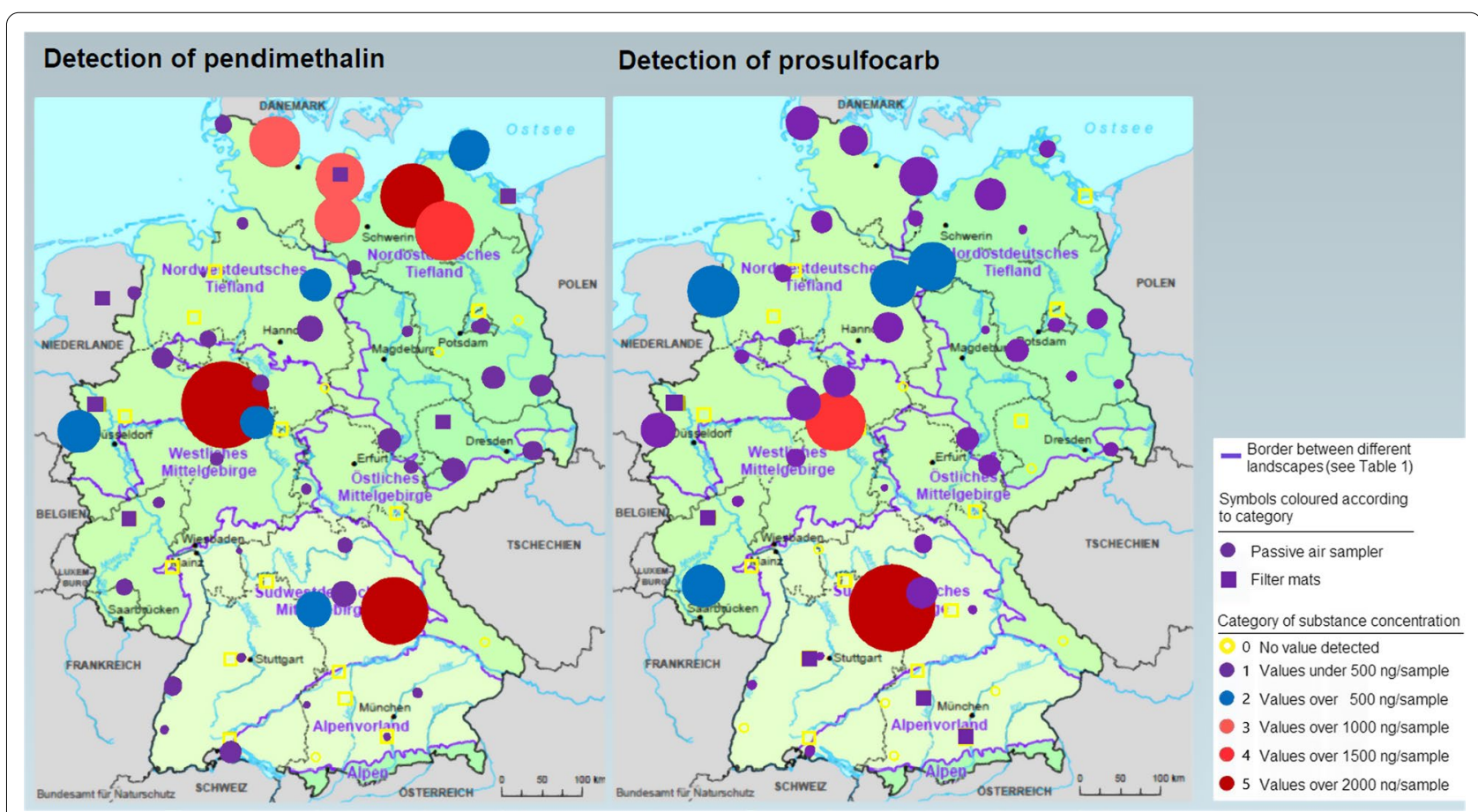

Fig. 7 Levels of pendimethalin and prosulfocarb

\section{Glyphosate, pendimethalin, and prosulfocarb}

Glyphosate was detected at all sampling sites in both passive air samplers and filter mats (Fig. 6), and concentrations peaked at $3176.8 \mathrm{ng} / \mathrm{sample}$ (median: $98.4 \mathrm{ng} /$ sample;

Table 3). AMPA was found at most but not all sites.

Empty squares represent no detection. For filter mats, only detection (yes/no) is given, without the actual concentrations.

The size of the circle is proportional to the maximum concentration detected (3916.8 ng/sample for pendimethalin and $2505.3 \mathrm{ng} / \mathrm{sample}$ for prosulfocarb).

The presence of pendimethalin and prosulfocarb adversely affects organic farming. Figure 7 shows the spatial distribution of these pesticides in our sampling. Pendimethalin was not detected at only five sites in passive air samplers. The values measured were high and the geographic distribution was widespread. The median of the values we measured (145.5 ng/sample) was below that of chlorothalonil (272.5 ng/sample). Chlorothalonil use was unauthorised in 2019, but application was permitted until May 5, 2020, after our sampling period. For prosulfocarb, we measured a maximum of $2505.3 \mathrm{ng} / \mathrm{sample}$ (median: $90.7 \mathrm{ng} / \mathrm{sample}$ ) in passive air samplers, and the pesticide was not detected at nine sites. Filter mats barely captured pendimethalin (maximum $18.3 \mathrm{ng} / \mathrm{m}^{3}$, five values detected) or prosulfocarb (maximum $5.5 \mathrm{ng} / \mathrm{m}^{3}$, five values detected). The spatial distribution of multiple other pesticides and related products is given in the main report [13], as well as the analysis of honeybee bread and tree bark and a comparison of the major pesticides across sampling methods.

In the passive air samplers, our findings identified landscape classification and agricultural intensity as important factors influencing most of the values measured. The distance to the nearest potential source or an association with organic farming had little influence on the values, with the exception of metolachlor levels, which were significantly lower in sites of organic farming (Additional File 13). The data are linked in a complex manner and must be considered separately for each substance examined. Additional File 14 lists the results of the statistical analysis for passive air samplers. Since only 20 filter mats from ventilation systems were available, the statistical data are not included here.

\section{Are pesticides and related products detectable in ambient air in Germany?}

So far, the only available data on pesticides and their related products in ambient air in Germany was the tree bark study of 2018 [10]. The present study expands this database and is still the first of its kind. A large number of pesticides and related substances were detected in German air. Glyphosate, chlorothalonil, metolachlor, 
pendimethalin, and terbuthylazine were abundant, and high concentrations of prosulfocarb were also found. The concentrations collected in the PUF disks and PEFs varied greatly and were not restricted to values close to the quantification limits.

\section{Is transport of pesticides and related substances in the air possible beyond the spray drift range?}

The number of substances detected and their levels in the samples enabled the distinction between polluted and less polluted locations [13] and the assessment of factors influencing contamination. Although the pollution was generally higher in agriculturally intense regions, pesticides were also found in remote locations. Mediumrange transport of these airborne substances is the most likely explanation. This has not yet been assumed for currently used pesticides. In general, the concentrations we found could be explained by several factors, such as landscape classification and agricultural activity. However, variables favouring medium-range transport, such as soil erosion, wind conditions, and topography, must also be considered and this should be done on a substance-specific basis.

\section{Is pesticide identification limited to passive air samplers or can pesticides also be detected in other materials exposed to ambient air?}

The detection of pesticides and their related substances is not confined to passive air samplers. In samples of filter mats from ventilation systems, a wide range of substances was detected as well. Similar to the findings in PEFs, glyphosate was detected in all samples. Furthermore, filter mats collect a different range of substances. Twenty nine out of 65 substances were only detected in filter mats. It is likely that substances specific to filter mats originate from soil and dust particles in the air that ventilations systems are designed to collect.

\section{Discussion}

\section{Comparison with other European studies}

So far, it is difficult to gain a conclusive overview of airborne pesticides in Europe. The few recent data on airborne pesticides focus on different ranges of pesticides and use different collection methods.

Most of these studies excluded glyphosate; only the French study by Marliere et al. [32] measured this pesticide. This comprehensive study collected airborne pesticides using Partisol ${ }^{\mathrm{TM}}$ Sequential Air Samplers for particulate matter and analysed them for 74 pesticides and one metabolite (AMPA) [32]. We detected glyphosate in all passive air samplers and filter mats, not surprisingly as it is the most widely used plant-protection product in Germany [38]. In France, glyphosate was detected in over
$80 \%$ of samples, which were collected at a flow rate of 30 $\mathrm{m}^{3} / \mathrm{h}$ over $48 \mathrm{~h}$. The findings of that study suggest that glyphosate is generally present in ambient air.

Altogether, 42 substances were detected in the air of mainland France. Glyphosate, lindane, metolachlor, pendimethalin, and triallate had a median above zero. Prosulfocarb and folpet had the highest air concentrations. Samples of semi-volatile substances were collected over 7 days with a flow rate of $24 \mathrm{~m}^{3} / \mathrm{d}$. This rate increased to $720 \mathrm{~m}^{3} / \mathrm{d}$ for glyphosate, glufosinate, and AMPA, which were collected over $48 \mathrm{~h}$.

The general sampling rates in the French study for semi-volatile substances is very low compared to the Swedish data [14, 33], which was derived from active sampling at a rate of $400 \mathrm{~m}^{3} / \mathrm{d}$ over 1 week but did not measure glyphosate. A total of 116 substances were analysed, the majority in the glass fibre and PUF partition of the sampling cartridge. Altogether, 45 substances were detected in the PUF at the Hallahus sampling station in the Swedish study [33], which is a comparable collection medium to our passive air sampler. However, six substances were only found under the quantification limit. Chlorpyrifos, prosulfocarb, terbuthylazine, and triallate are currently used pesticides that were most frequently detected. The highest concentrations were observed for prosulfocarb. Pendimethalin was detected in nearly $40 \%$ of all samples; similar to chlorpyrifos, pendimethalin is not approved for use in Sweden.

In Italy, Estellano et al. [34] assessed the occurrence and seasonal variations of 10 current-use pesticides (chlorpyrifos, chlorpyrifos methyl, malathion, terbufos, diazinon, disulfoton, dacthal, trifluralin, pendimethalin, and chlorothalonil). All 10 pesticides were detected. Chlorpyrifos in both forms was identified as the most frequent pesticide with the highest concentrations. Chlorothalonil, which we detected at almost all sites and with very high levels, was the least detected pesticide in the Italian study. Pendimethalin was surprisingly more commonly detected in urban rather than rural settings.

An earlier extensive study in France used a Partisol 2000 low-volume sampler [35]. Between 2006 and 2008, samples were collected and analysed for 56 currently used pesticides, of which 41 were detected. The herbicides trifluralin, acetochlor, and pendimethalin and the fungicide chlorothalonil were detected at a frequency of $52-78 \%$. This corresponds to our findings in Germany, where trifluralin and acetochlor are no longer approved but pendimethalin and chlorothalonil were widely detected.

Degrendele et al. [36] assessed 27 currently used pesticides and 10 persistent organic pollutants in the Czech Republic using a high-volume air sampler exposed for 1 week and an air volume around $600 \mathrm{~m}^{3} / \mathrm{d}$ as well as a 
Cascade impactor air sampler. The emphasis of the study was the determination of gas-particle partitioning and particle size distribution in current-use pesticides and persistent organic pollutants. Isoproturon, metazachlor, chlorpyrifos, terbuthylazine, S-metolachlor, and fenpropimorph were detected in more than $65 \%$ of samples. Chlorpyrifos, metazachlor, acetochlor, isoproturon, and S-metolachlor were identified as substances with a total combined maximum of (gas particulate phase) concentrations exceeding $100 \mathrm{pg} / \mathrm{m}^{3}$. The presence of terbuthylazine varied by season. The substances our study identifies as widespread, such as chlorothalonil, pendimethalin, dimethenamid, and prosulfocarb, were not analysed here. However, the occurrence of chlorothalonil, chlorpyrifos, and pendimethalin in European air and worldwide had been established in 2012 by Koblizkova et al. [18].

In comparison, the present study covers the widest range of analysed substances. With 109 substances detected, the range of pesticides known to be airborne is extended significantly. Pesticides detected with higher frequencies, such as chlorothalonil, metolachlor, pendimethalin, terbuthylazine, and prosulfocarb, were also frequently identified in other studies. The metabolite prothioconazole-desthio was assessed in the Sweden study but not discussed [14]. Dimethenamid was included in the France study but was only rarely detected (frequency $<5 \%$ ). Overall, we detected pendimethalin and prosulfocarb in over four fifths of the samples and at high levels. The medium-distance transport of these pesticides is clearly illustrated by Kreuger and Lindström [14], who found pendimethalin in nearly $40 \%$ of all samples even though this pesticide is not approved for use in Sweden and probably originated in neighbouring countries such as Denmark, Germany, and Poland.

In general, substances that were not detected in the earlier studies had a lower detection frequency in our data set. These pesticides contribute to the overall pesticide load in the air but may have potential ecotoxicological effects and still result in high air concentrations because of their seasonal application. Their relevance must be assessed further.

However, agriculture is country-specific, with unique environmental conditions in soil and climate. This results a distinctive variety of cultivars, which in turn determine pesticide application. In a comparison with the Swedish PUF data from Hallahus (2017), we found 24 substances that were detected in both countries. Twenty one substances were detected in Sweden but not Germany and 43 substances were detected in Germany but not Sweden. Nine substances detected in Germany were targeted but not found in the Sweden data set. The findings were similar for glass fibre filters and filter mats (Additional File 15).

Pendimethalin and chlorpyrifos are not approved for use in Sweden but were detected at low levels. For chlorpyrifos, this was true for Germany as well. Because of varying environmental conditions, levels of airborne pesticides may vary between areas and countries and also between years. The growing interest in this topic renders is likely that more insights into these variations will be possible in the future.

\section{Comparability to other passive sampler data and concentration estimates for pendimethalin and chlorothalonil}

Pendimethalin and chlorothalonil are among the most commonly detected pesticides in German air. For economic reasons, our findings give the total values measured in three PUF disks over 7 months. To compare the data to passive air sampler data, the pooled quantity must be divided by three. We used the calculation given by Estellano et al. [34] to estimate air concentrations of pendimethalin, chlorothalonil, and chlorpyrifos-ethyl (Additional File 16).

Pendimethalin has been detected in air samples worldwide [18]. The more recent data compiled by Estellano et al. [34] in Italy used passive air sampling to measure nine current-use pesticides, including pendimethalin and chlorothalonil. The detection frequency of pendimethalin was below $25 \%$ of samples. Surprisingly, higher concentrations were found at urban sites (maximum: $1500 \mathrm{pg}$ / $\mathrm{m}^{3}$ in spring). During other sampled seasons, concentrations did not exceed $280 \mathrm{pg} / \mathrm{m}^{3}$. We compared these values with data from the Czech Republic in 2012 [18] and Canada in 2008 [15] in 2010 [16]. Higher values were detected in France in 2010 [35] using Partisol 2000 lowvolume samplers, with a maximum of $117,330 \mathrm{pg} / \mathrm{sample}$ and an average $1840 \mathrm{pg} / \mathrm{m}^{3}$; the frequency of detection was $66 \%$.

The German results identify this pesticide more often (frequency: $89.8 \%$ ) but at lower levels comparable to those recorded in France in 2010. The maximum for pendimethalin was $4796 \mathrm{pg} / \mathrm{m}^{3}$ and was by no means a singular value. Of the seven values that exceeded $1000 \mathrm{ng} /$ sample, an average concentration of $2405 \mathrm{pg} / \mathrm{m}^{3}$ was measured. The German average over all 49 sites, including five sites, where the pesticide was not detected, is $543 \mathrm{pg} / \mathrm{m}^{3}$. These findings may reflect the wide use of pendimethalin in Germany today. Since this study offers only one value over 7 months, it must be expected that the concentrations of pendimethalin are significantly higher during times when the pesticide is applied (spring and autumn). Pendimethalin and prosulfocarb were of 
special interest in the present study because of their effects on organic farming [11].

Chlorothalonil was widely detected (frequency: 95.9\%) but was at the end of its approval period in Germany (May 2020). Estellano et al. [34] detected chlorothalonil in fewer than $25 \%$ of samples and during only two seasons, with a peak measurement of $40 \mathrm{pg} / \mathrm{m}^{3}$. In Germany, chlorothalonil concentrations reached an average of $775 \mathrm{pg} / \mathrm{m}^{3}$, even when two samples without detection are included. The highest concentration was $3030 \mathrm{pg} / \mathrm{m}^{3}$, and the average of seven samples that exceeded $1000 \mathrm{ng} /$ sample was $2291 \mathrm{pg} / \mathrm{m}^{3}$. These numbers are in line with data reported by Koblizkova et al. [18], where a 2500 pg/ $\mathrm{m}^{3}$ concentration was recorded in Paris and $340 \mathrm{pg} /$ $\mathrm{m}^{3}$ in Kosetice (Czech Republic). However, Coscollà et al. [35] reported considerably higher levels (maximum: $107,000 \mathrm{pg} / \mathrm{m}^{3}$ ) with an average concentration of $12,150 \mathrm{pg} / \mathrm{m}^{3}$, but at a lower detection frequency of $58 \%$.

Abundant data are available for chlorpyrifos in passive air samplers, which is not approved for use in Germany even though it was detected along the western and eastern borders. The highest value corresponded to $280 \mathrm{pg} /$ $\mathrm{m}^{3}$. Recent data from Chile suggest an air concentration range between 444 and $14,624 \mathrm{pg} / \mathrm{m}^{3}$ when the pesticide is actively applied [37].

\section{Temporal variations in pesticide levels}

Our data represent sums over the entire measurement period and do not reflect temporal patterns, so whether the airborne concentrations were relatively constant over the collection period or differed by season or event is unknown. The temporal pattern of exposure was not an aim of this study, but it is highly relevant for a toxicological assessment.

Earlier studies had already shown that temporal variations are detectable using passive air samplers [34, 36].

Sweden is the first European country to conduct longterm active sampling of airborne pesticides at rural sites surrounded by forests and located more than $1 \mathrm{~km}$ away from treated fields [14]; weekly data are available from the University of Uppsala [33]. Kreuger and Lindström [14] showed that most of the pesticides and their related substances were captured in the glass fibre filter and the first PUF disk, while only $4 \%$ of the total pesticide content was found in the AmberLite resin and second PUF disk. Additional File 17 lists the number of substances detected in 2017 at the Hallahus site, the southernmost measuring station of the Swedish network. The weekly data for the glass fibre filter and the PUF disk are listed separately. Figure 8 shows a graphic summary of the data. Ten to 35 substances of the 101 in the testing protocol were detected in the PUF disk. The glass fibre filters were analysed for 115 substances, adding six to 42 substances to the findings. Figure 8 shows the number of substances detected in the PUF and glass fibre filter.

The Swedish data display a clear seasonal variation, with the number of substances detected decreasing in autumn (Additional File 17). A weekly maximum of 59 substances was detected twice in the first half of the year. In autumn (October 30, 2017), only 17 substances remained. The median over the measurement period was 36.5 for all substances in the glass fibre filter and PUF disk. Prosulfocarb and $\gamma-\mathrm{HCH}$ were detected consistently throughout the year [14]. Chlorpyrifos, propyzamide, and triallate were also detected during much of the year. In areas of intensive agriculture in Germany, a continuous presence of pesticide mixtures in ambient air is, therefore, highly likely and should be the subject of further investigation.

\section{Comparing Swedish data with findings from passive air samplers and filter mats}

The two sampling methods in our study are likely to reflect airborne pesticides and their related products from differing origins. The PUF disk in the passive air sampler is designed to sample volatile and semi-volatile substances and exclude particles [30], while filter mats capture dust and sometimes pollen. Therefore, filter mats capture a different range of substances. Twenty-nine substances in filter mats were not detected in the passive air samplers, while 44 substances were detected only in the passive air samplers and not in filter mats. However, while we assess these methods separately, the Swedish study $[14,33]$ measured substances in glass fibre and PUF disks simultaneously. The number of substances detected in the Swedish study $[14,33]$ peaked at 59. In one example, 37 substances were detected in the glass fibre filter and 32 in the PUF disk. The number of substances detected by both methods, in this case 10 , was subtracted from the total to remove duplicates. We detected $36 \mathrm{sub-}$ stances in filter mats and 33 in PUF disks, much lower than the 59 detected in Sweden in glass fibre filters and PUF disks at a peak period.

Our data for Germany are, therefore, likely to underestimate the pesticide load at any one point. Combining filter and PUF disk measurements in a passive air sampler may increase these numbers significantly.

For future passive air sampler measurements, it may be worthwhile to analyse the PEF not only for glyphosate but for the 500 pesticides and related substances assessed in filter mats so as to broaden the detectable range of substances.

\section{Medium- and long-range transport}

In our statistical analysis, we defined distances from a potential source for all measured sites so as to separate 


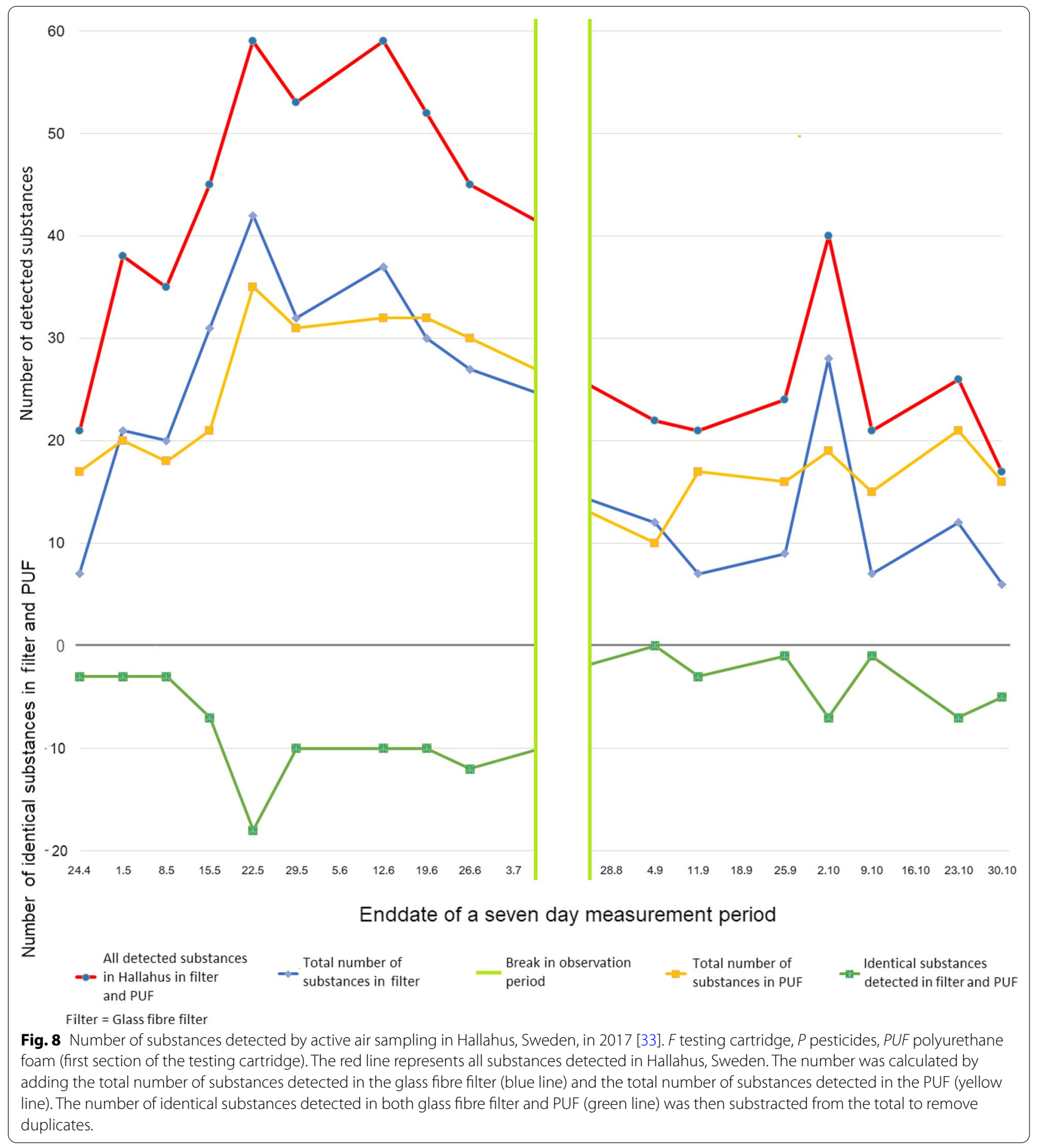

effects from spray drift, which will only occur in proximity to a field from airborne pesticides that travelled a longer distance in the air. Long-range transport in this context is set when a source is more than $1000 \mathrm{~m}$ away from the measurement site.
The FOCUS report [38] took a broader view and defined short-range transport (SRT) as $0,001-1 \mathrm{~km}$, medium-range transport (MRT) as 1-1000 km, and longrange transport (LRT) as $>1000 \mathrm{~km}$ from the point of application. Kreuger and Lindström [14] detected many substances that did not originate in Sweden, as they are 
not authorised for use there, suggesting medium-range transport according to the FOCUS criteria. In Germany, which is centrally located in Europe, a similar phenomenon is likely. We detected chlorpyrifos at several eastern and western sites close to the borders [13], although the use of chlorpyrifos is not permitted in Germany.

Additional File 18 contains the European Food Safety Authority (EFSA) conclusions on the potential for volatilisation and long-range transport of the most widely detected pesticides in this study (glyphosate, metolachlor, pendimethalin, terbuthylazine, and prosulfocarb). Medium- and long-range transport are not distinguished in the EFSA reports. The vapour pressure of these substances classifies all of them as having low volatility [13], with the exception of metolachlor, which is of medium volatility. EFSA maintains that a substantial loss of active substance to the air is not to be expected; a loss to the air over the short range is only considered for pendimethalin. The potential for medium- or long-range transport is disregarded entirely. In view of our findings, the assumptions incorporated into the approval processes concerning the release of pesticides to the air are not adequate. There is a need to revise current EFSA estimates of pesticide releases to include estimates for medium- and longrange air transport. This is particularly relevant for the renewal of the approval for glyphosate.

Our findings indicate that a certain degree of longrange transport between continents is also likely. Current-use pesticides can be expected to travel far from their application sites and be present in any air mass passing over land. Bearing in mind that their environmental fate depends on their chemical properties, a worldwide distribution, as observed already for POPs, nevertheless must be considered possible.

\section{Conclusion}

Our findings indicate that pesticides and their related substances are ubiquitously present in ambient air in the Federal Republic of Germany. There is evidence that pesticides and their related substances can travel through the air at least in the medium and possibly also in the long range. This has long been known for substances listed under the Stockholm Convention, such as DDT, PCBs, and $\gamma-\mathrm{HCH}$ [39]. For pesticides and their related substances in current use in Germany, this is demonstrated to this extent for the first time. The findings show clearly that more than one substance is present in sometimes considerable loads at any location. Considering all available data, a distinct seasonal variation must be expected that may be primarily related to the time of pesticide application. Future active sampling is likely to yield better insights.
The passive air sampler was a valuable tool for classifying airborne pesticide loads. The number of pesticides and their measured concentrations yield a good indication of the exposure at the location.

However, we must be aware that passive air sampling may detect fewer airborne pesticides than active sampling. Analysis of the PEF in the passive air sampler for the 500 pesticides may increase the number of substances detected significantly. In addition, the findings for the filter mats indicate that the PEF may likewise collect a different range of substances that are currently unidentified.

Because they are simple to use, passive air samplers are increasingly employed in Europe and other regions. Compilation of all available information into a common database could be valuable for site evaluation and comparison of airborne pesticide levels.

Active monitoring of the airborne concentrations of these substances is nonetheless required. Only active sampling can yield reliable air concentration measurements in the short term. In Germany, the Bundesamt für Verbraucherschutz und Lebensmittelsicherheit (BVL; Federal Office of Consumer Protection and Food Safety) is planning to operate three sampling sites in the next years [40]. Because of the technical requirements, the number of sampling site will always be limited.

All further monitoring must include glyphosate, which was detected universally.

The pesticide approval procedure used by EFSA [4146] underestimates the loss of pesticides to the atmosphere and their potential for medium- and long-range transport for all pesticides that were frequently detected (Additional file 18). Accordingly, a revision of the current EFSA pesticide approval procedure to include a realistic estimate for the potential loss of a pesticide to the air and its potential for medium- and long-range transport is recommended.

Pesticide application reduction as proposed by the European Union Commission's proposal in May 2021 to $50 \%$ by 2030 [1] is an important first step in reducing the air load and relieving problems associated with pesticide application. However, it is not clear from our current data whether airborne pesticides and their related substances are detected as a general side effect from conventional farming. It is possible that our observations are related to specific substances with an exceptionally high potential for airborne transport. In the first case, the general volume of pesticides used should be reduced. In the second case, regulatory management of substances prone to air transport could be an appropriate and expedient solution.

The lack of data does not permit conclusions about the health effects of inhalational exposure to pesticide mixtures, which are likely chronic and must be investigated. 
Similarly, effects on sensitive ecosystems require further study.

In addition to potential health and ecological effects, the concentrations of pesticides in ambient air also exert significant economic consequences. European Commission regulation 834/2007 governs the control of organic agriculture and its products to ensure that synthetic chemical additives such as pesticides and fertilisers do not interfere with the production process. However, organic farmers cannot protect their crops against air pollution by pesticides such as pendimethalin and prosulfocarb, which results in produce that cannot be marketed as organic.

A search for alternatives for these pesticides is necessary if the European Union's goal of coexistence anchored in EC Basic Organic Regulation No. 834/2007 between conventional and organic forms of production is to apply.

\begin{abstract}
Abbreviations
AMPA: Aminomethylphosphonic acid; BVL: Bundesamt für Verbraucherschutz und Lebensmittelsicherheit (Federal Office of Consumer Protection and Food Safety); DCBP-pp: Dichlorobenzophenone; DDT: Dichlorodiphenyltrichloroethane; EFSA: European Food Safety Authority; GAPS: Global Atmospheric Passive Sampling; HCB: Hexachlorobenzene; y-HCH: Gamma-hexachlorocyclohexane; MCPA: 2-Methyl-4-chlorophenoxyacetic acid; PBO: Piperonyl butoxide; PEF: Polyester filter; POP: Persistent Organic Pollutants; PUF: Polyurethane foam.
\end{abstract}

\section{Supplementary Information}

The online version contains supplementary material available at https://doi. org/10.1186/s12302-021-00553-4.

Additional file 1: Vapour pressure categories for pesticides and estimated effects on air concentrations used by the European Food Safety Authority.

Additional file 2: Sampling site characteristics.

Additional file 3: Distribution of site characteristics in 49 passive air sampler sites.

Additional file 4: Distribution of site characteristics in 20 filter mat sites.

Additional file 5: Active substance, active substance classes, and quantification limits $(\mathrm{mg} / \mathrm{kg})$ used for polyurethane foam disks.

Additional file 6: Active substance, active substance classes, and quantification limits $(\mathrm{mg} / \mathrm{kg})$ in routine examination to determine pesticide residues according to ASU L 00.00-115 for materials from agriculture and horticulture with a low content of fat (used here for filter mats).

Additional file 7: List of pesticides and related substances registered in ASU L 00.00-115 with no or not entirely agricultural origin. See also Additional Files 4 and 6.

Additional file 8: Ventilation systems using filter mats in this study.

Additional file 9: Pesticides and related substances detected in passive air samplers, including DCBP-pp, HCB, PBO, and five PCBs

Additional file 10: Pesticides and related substances detected in filter mats, including anthraquinone and PBO.

Additional file 11: Substances detected in passive air samplers (PAS) and filter mats (FM).
Additional file 12: Figure S1. Aerial view of sampling site 1007-748 (Bayerischer Wald national park). Figure S2. Aerial view of sampling site 1000-740 (Brockengarten in the Harz national park)

Additional file 13: Results of the statistical analysis for the number of substances detected in passive air samplers given as a regression tree.

Additional file 14: Regression trees of pesticides and related substances frequently detected in passive air samplers without reference in the main text.

Additional file 15: Comparison between PUF, glass fibre filter, and filter mat data from Hallahus, Sweden 2017 and CSP 2019, Germany.

Additional file 16: Calculation of vair and concentrations for pendimethalin, chlorothalonil, and chlorpyrifos.

Additional file 17: Data sheets for substances detected in Hallahus, Sweden, in 2017.

Additional file 18: Vapour pressure and European Food Safety Authority conclusions on the potential volatilisation and capacity for long-range transport of active substances frequently detected in the present study

\section{Acknowledgements}

Initiators: Johannes Heimrath (Bürgerinitiative Landwende), Karl Bär (Umweltinstitut München), Stephan Paulke. Council of experts: Dr. Peter Clausing, Dr. Günther Lach (Lach\&Bruns), Rudolf Vögel (LfU Brandenburg), Dr. Bernhard Wagner (Wassergut Canitz GmbH), Sophia Guttenberger, Christine Vogt, Fabian Holzheid (all Umweltinstitut München), Heike Kirsten, Anna Satzger, Lena Korber, Johanna Bär (all Bündnis für eine enkeltaugliche Landwirtschaft), Bernhard Wagner. The authors thank all participants of the Citizen Science Project for providing locations or material, helping to collect the samples and contributing to the funding. The authors also thank Edanz (https://en-authorservices.edanz.com/) for editing a draft of this manuscript as well as Nadine Warkotsch (HS Augsburg) for her helpful suggestions.

\section{Authors' contributions}

All authors made substantial and equal contributions to the manuscript. All authors read and approved the final manuscript, with the exception of Frieder Hofmann, the founder of TIEM Environmental Monitoring and head of this project, who passed away from cancer before the manuscript was finalised.

\section{Funding}

This research was funded by the Bündnis für enkeltaugliche Landwirtschaft e. V., Klein Jasedow, Am See 1, 17440 Lassan (https://www.enkeltauglich.bio/) and Umweltinstitut München e.V., Goethestraße 20, 80336 München (https:// www.umweltinstitut.org).

\section{Availability of data and materials}

The data sets generated and/or analysed during the current study are available at https://www.enkeltauglich.bio/supplementing-data-enscieu.

\section{Declarations}

Ethics approval and consent to participate Not applicable.

\section{Consent for publication}

This publication draws on the results of measurements taken in Sweden that are available to the public via the website of Swedish University of Agricultural Sciences at https://www.slu.se/en/departments/aquatic-sciences-assessment/ environment/pesticide_monitoring/pesticide_data/.

\section{Competing interests}

The authors declare that they have no competing interests. 


\begin{abstract}
Author details
${ }^{1}$ TIEM Integrated Environmental Monitoring, 95615 Marktredwitz, Germany. ${ }^{2}$ Ökologiebüro, TIEM Integrated Environmental Monitoring, 28205 Bremen, Germany. ${ }^{3}$ Institute of Statistics, University of Bremen, 28359 Bremen, Germany. ${ }^{4}$ TIEM Integrated Environmental Monitoring, Hohenzollernstr. 20,44135 Dortmund, Germany. ${ }^{5}$ Schweisfurth Stiftung, Rupprechtstr. 25, 81636 München, Germany.
\end{abstract}

Received: 4 May 2021 Accepted: 7 September 2021

Published online: 07 October 2021

\section{References}

1. European Commission (2020) Farm to fork strategy. https://ec.europa.eu/ food/horizontal-topics/farm-fork-strategy_en. Accessed 10. Oct 2020

2. Schäffer A, Filser J, Frische T, Gessner M, Köck W, Kratz W, Liess M, Nuppenau E-A, Roß-Nickoll M, Schäfer R, Scheringer M (2018) Der stumme Frühling-Zur Notwendigkeit eines umweltverträglichen Pflanzenschutzes. Diskussion Nr. 16. Accessed: 23 Jul 2020

3. Umweltbundesamt (UBA) Zulassung von Pflanzenschutzmitteln. https:// www.umweltbundesamt.de/themen/chemikalien/pflanzenschutzmittel/ zulassung-von-pflanzenschutzmitteln. Accessed 12 Jun 2019

4. European Food Safety Authority (EFSA) (2014) Guidance on the assessment of exposure of operators, workers, residents and bystanders in risk assessment for plant protection products. EFSA J 12(10):3874. https://doi. org/10.2903/j.efsa.2014.3874

5. Bundesamt für Verbraucherschutz und Lebensmittelsicherheit (BVL) (2016) Bekanntmachung über die Mindestabstände bei der Anwendung von Pflanzenschutzmitteln zum Schutz von Umstehenden und Anwohnern, die der Zulassung von Pflanzenschutzmitteln zugrunde gelegt werden. (BVL 16/02/02). Bundesanzeiger. BAnz AT 20.05.2016 B5:2

6. Bayerische Landesanstalt für Landwirtschaft (LfL) (2012) Neue Anwendungsbestimmungen für Clomazone-haltige Rapsherbizide: Rapsherbizidmarkt 2012 im Umbruch.: Institut für Pflanzenschutz-Herbologie https://www.lfl.bayern.de/mam/cms07/ips/dateien/clomazone_neue_ auflagen_inet-pdf_12.pdf. Accessed 20 Jun 2021

7. Sonnentor Kräuterhandels $\mathrm{GmbH}$, Herbaria Kräuterparadies $\mathrm{GmbH}$, Weleda AG, Völkel GmbH \& Co. KG, Rosenhof Naturkost GbR, SALUS Haus Dr. med. Otto Greither Nachf. GmbH \& Co. KG, Biokräuterhof Walter Sturm $\mathrm{GmbH}$, Biolandhof Cordes (2016) Open Letter: Ferntransport bestimmter Pflanzenschutzmittel—Hier: dringender Handlungsbedarf. Signed by: Stefan Palme, Gut Wilmersdorf GbR. https://www.bioland.de/fileadmin/ dateien/HP_Dokumente/Pressemitteilungen/160607_Unternehme rbrief_an_BVL_BMEL___Pestizidschaeden.pdf. Accessed 28 Jan 2020.

8. European Union (EU) (2018) Regulation (EU) 2018/848 of the European Parliament and of the Council of 30 May 2018 on organic production and labelling of organic products and repealing Council Regulation (EC) No. 834/2007. Official Journal of the European Union. L 150/1. https://eur-lex. europa.eu/legal-content/EN/TXT/?uri=CELEX:32018R0848.

9. Hofmann F, Schlechtriemen U (2015) Durchführung einer Bioindikation auf Pflanzenschutzmittelrückstände mittels Luftgüte-Rindenmonitoring, Passivsammlern und Vegetationsproben. Potsdam: Ministerium f. Ländliche Entwicklung, Umwelt und Landwirtschaft. http://www.tieminfo.de/. cm4all/uproc.php/0/Publikationen/2015\%20Hofmann\%26Schlechtriemen\%20\%20Bioindikation\%20PSM\%20fb\%20lugv\%20147.pdf?_=16e5a a8c91d\&cdp=a. Accessed 17 Dec 2018.

10. Hofmann F, Schlechtriemen U, Kruse-Plaß M, Wosniok W (2019) Biomonitoring der Pestizid-Belastung der Luft mittels Luftgüte-Rindenmonitoring und Multi-Analytik auf > 500 PSM-Wirkstoffe sowie Glyphosat. TIEM Integrierte Umweltüberwachung for: Bündnis für eine Enkeltaugliche Landwirtschaft e.V., Am See 1, 17440 Lassan. http://www.tieminfo.de/. cm4all/uproc.php/O/Publikationen/Bericht-H18-Rinde-20190210-1518-1. pdf?_=16e5a98b3af\&cdp=a. Accessed 23 Nov 2020.

11. Hofmann F, Schlechtriemen U (2017) Biomonitoring der Immissionsbelastung von Glyphosat, Glufosinat und AMPA sowie weiteren PSM-Wirkstoffen mittels Luftgüte-Rindenmonitoring-Ergebnisse Screening 2017. München. https://doi.org/10.13140/RG.2.2.12733.15842

12. Krüger M, Lindner A, Heimrath J (2016) Nachweis von Glyphosat im Urin freiwilliger, selbstzahlender Studienteilnehmer "Urinale 2015." Text: http:// www.urinale.org/wp-content/uploads/2016/03/PK-Text-Handout.pdf (tables and graphs: http://www.urinale.org/wp-content/uploads/2016/ 03/PK-Daten-Handout.pdf). Accessed 9 Feb 2021.

13. Kruse-Plaß M, Schlechtriemen U, Wosniok W (2020) Konzeption: F. Hofmann. Pestizid-Belastung der Luft. Eine deutschlandweite Studie zur Ermittlung der Belastung der Luft mit Hilfe von technischen Sammlern, Bienenbrot, Filtern aus Be- und Entlüftungsanlagen und Luftgüte-Rindenmonitoring hinsichtlich des Vorkommens von Pestizid-Wirkstoffen, insbesondere Glyphosat. TIEM Integrierte Umweltüberwachung: For: Bündnis für eine Enkeltaugliche Landwirtschaft e.V., Am See 1, 17440 Lassan. Available from: https://www.enkeltauglich.bio/?page_id=1080. Accessed 30 Nov 2020.

14. Kreuger J, Lindström B (2019) Long-term monitoring of pesticides in air and atmospheric deposition in Sweden. IUPAC; Ghent, Belgium 20 May 2019. Swedish University of Agricultural Sciences (SLU), Uppsala, Sweden

15. Gouin T, Wania F, Ruepert C, Castillo L (2008) Field testing passive air samplers for current use pesticides in a tropical environment. Environ Sci Technol 42:6625-6630. https://doi.org/10.1021/es8008425

16. Hayward S, Gouin T, Wania F (2010) Comparison of four active and passive sampling techniques for pesticides in air. Environ Sci Technol 44(9):3410-3416. https://doi.org/10.1021/es902512h

17. Herkert N, Spak S, Smith A, Schuster J, Harner T, Martinez A, Hornbuckle K (2018) Calibration and evaluation of PUF-PAS sampling rates across the Global Atmospheric Passive Sampling (GAPS) network. Environ Sci: Processes Impacts 20:210-219. https://doi.org/10.1039/c7em00360a

18. Koblizkova M, Lee SC, Harner T (2012) Sorbent impregnated polyurethane foam disk passive air samplers for investigating current-use pesticides at the global scale. Atmos Pollut Res 3:456-462. https://doi. org/10.5094/APR.2012.052

19. Zhang $X$, Brown T, Ansari A, Yeun B, Kitaoka K, Kondo A, Lei Y, Wania $F$ (2013) Effect of wind on the chemical uptake kinetics of a passive air sampler. Environ Sci Technol 47(14):7868-7875. https://doi.org/10. 1021/es401486f

20. Zhang X, Wania F (2012) Modeling the uptake of semivolatile organic compounds by passive air samplers: importance of mass transfer processes within the porous sampling media. Environ Sci Technol 46(17):9563-9570. https://doi.org/10.1021/es302334r

21. Zhang X, Tsurakawa M, Nakano T, Lei Y, Wania F (2011) Sampling medium side resistance to uptake of semivolatile organic compounds in passive air samplers. Environ Sci Technol 45(24):10509-10515. https://doi.org/10.1021/es2032373

22. Morshed MM, Omar D, Mohamad R, Wahed S (2011) Determination of glyphosate through passive and active sampling methods in a treated field atmosphere. Afr J Agricul Res 6(17):4010-4018. https://doi.org/10. 5897/AJAR11.533

23. Hofmann F, Schlechtriemen U, Kruse-Plaß M, Wosniok W (2019) Pilot-Monitoring 2018-zur Evaluation geeigneter PassivsammlerVerfahren für ein Citizen-Science-Projekt im Jahr 2019-Baumrinde, Petersilie, Passivsammler (PAS-PUF, PAS-XAD, PMF-XAD), Luftfilter. TIEM Integrierte Umweltüberwachung: For: Bündnis für eine Enkeltaugliche Landwirtschaft e.V., Am See 1, 17440 Lassan. http://www.tieminfo.de/. cm4all/uproc.php/0/Publikationen/Pilotmonitoring\%202018.pdf?_= 173bf11ab28\&cdp=a. Accessed: 23 Nov 2020

24. Pozo K, Harner T, Wania F, Muir DCG, Jones KC, Barrie LA (2006) Toward a global network for persistent organic pollutants in air: results from the GAPS study. Environ Sci Technol 40(16):4867-4873. https://doi.org/ 10.1021/es060447t

25. Kruse-Plaß M (2021) Vergleich zwischen der Erfassung semi-volatiler Pestizide im PUF des TE-200-PAS Passivsammlers und dem TIEM technic Passivsammler. http://tieminfo.de/.cm4all/uproc.php/0/Publi kationen/Vergleich\%20Te\%20200\%20PAS\%20TIEM\%20technic\%20PAS. pdf?_=17b3584f0b0\&cdp=a. Accessed: 23 Jun 2021

26. Bundesamt für Verbraucherschutz und Lebensmittelsicherheit (BVL) (2018) Untersuchung von Lebensmitteln-Multiverfahren zur Bestimmung von Pestizidrückständen mit GC und LC nach Acetonitril-Extraktion/Verteilung und Reinigung mit dispersiver SPE in pflanzlichen Lebensmitteln - Modulares QuEChERS-Verfahren. Beuth Verlag, Berlin

27. Yusà Y, Coscollà C, Mellouki W, Pastor A, de la Guardia M (2009) Sampling and analysis of pesticides in ambient air. J Chromatogr A 1216(15):2972-2983 
28. EU Reference Laboratories for Residues of Pesticides (2020) SANTE/11813/2019. https://www.eurl-pesticides.eu/userfiles/file/EurlA LL/AqcGuidance_SANTE_2019_12682.pdf. Accessed: 28 Jul 2020

29. KWALIS Qualitätsforschung Fulda GmbH (2021) Validierungsuntersuchungen zur Bestimmung von Glyphosat (N-phosphonomethylglycin) und AMPA (Aminomethylphosphonic acid) in PEF-Filtermaterialien (Polyester-Filtermatten). http://tieminfo.de/PUBLIKATIONEN/. Accessed: 24 Jul 2021

30. Eng A, Harner T, Pozo K (2014) A prototype passive air sampler for measuring dry deposition of polycyclic aromatic hydrocarbons. Environ Sci Technol Lett 1(1):77-81. https://doi.org/10.1021/ez400044z

31. Breiman L, Friedman J, Stone C, Olshen R (1984) Classification and regression trees. Chapman and Hall/CRC.

32. Marliere F, Letinois L, Salomon M (2020) Résultats de la Campagne Nationale Exploratoire de mesure des résidus de Pesticides dans l'air ambiant (2018-2019) Ineris: Laboratoire Central de Surveillance de la Qualité de l'Air. Available from: https://www.lcsqa.org/fr/rapport/resul tats-de-la-campagne-nationale-exploratoire-de-mesure-des-residus-depesticides-dans. Accessed 12 Nov 2020.

33. SLU-Sveriges lantbruksuniversitet (Swedish University of Agricultural Sciences). Environmental assessment. https://www.slu.se/en/depar tments/aquatic-sciences-assessment/environment/pesticide_monit oring/pesticide_data/. Accessed: 18 Dec 2020.

34. Estellano VH, Efstathiou C, Pozo K, Corsolini S, Focardi S (2015) Assessing levels and seasonal variations of current-use pesticides (CUPs) in the Tuscan atmosphere, Italy, using polyurethane foam disks (PUF) passive air samplers. Environ Pollut 205:52-59. https://doi.org/10.1016/j.envpol.2015. 05.002

35. Coscollà C, Colin P, Yahyaoui A, Petrique O, Yusà V, Mellouki A, Pastor A (2010) Occurrence of currently used pesticides in ambient air of Centre Region (France). Atmos Environ 44(32):3915-3925. https://doi.org/10. 1016/j.atmosenv.2010.07.014

36. Degrendele C, Okonski K, Melymuk L, Landlová L, Kukučka P, Audy O, Kohoutek J, Čupr P, Klánová J (2016) Pesticides in the atmosphere: a comparison of gas-particle partitioning and particle size distribution of legacy and current-use pesticides. Atmos Chem Phys 16(3):1531-1544. https:// doi.org/10.5194/acp-16-1531-2016

37. Pozo K, Llanosa Y, Victor H, Estellano VH, Cortése S, Jorquera H, Gerlia L, Pozo K, Encina F, Palmah R, Focardid S (2016) Occurrence of chlorpyrifos in the atmosphere of the Araucanía Region in Chile using polyurethane foam-based passive air samplers. Atmos Pollut Res 7(4):706-710. https:// doi.org/10.1016/j.apr.2016.03.003

38. FOCUS Air Group (2008) Pesticides in air: considerations for exposure assessment. European Commission, Health \& Consumer Protection Directorate-General, SANCO/10553/2006. Rev 2 June 2008, 327pp.

39. United Nations Environment Programme (UNEP) All POPs listed in the Stockholm Convention. http://chm.pops.int/TheConvention/ThePOPs/ ListingofPOPs/tabid/2509/Default.aspx. Accessed 1 Oct 2020.

40. Bolz H, Kubiak R (2020) Zur Information für die Öffentlichkeit: Machbarkeitsanalyse für ein Monitoring über Rückstände in unbehandelten Flächen und auf unbehandelten Kulturen über die Verfrachtung von Pflanzenschutzmittelwirkstoffen RLP AgroScience GmbH, Institut für
Agrarökologie, Breitenweg 71, 67435 Neustadt an der Weinstraße. Available from: https://eur02.safelinks.protection.outlook.com/?url=https\% 3A\%2F\%2Fwww.bvl.bund.de\%2FSharedDocs\%2FFachmeldungen\% 2F04_pflanzenschutzmittel\%2F2020\%2F2020_08_28_Fa_Veroeffentlichu ng_Machbarkeitsanalyse_Luftmonitoring.html\&amp;data=02\%7C01\% 7C\%7Cad8c037140d444f9c95608d84db3d570\%7C84df9e7fe9f640afb4 35aаaаaаaаaаaа\%7C1\%7C0\%7C637344782055084474\&amp;sdata=Z\% 2Bb\%2BSqPfwh5FBHcl4CFIN4kQIJf2YDNNECQwroCE8F8\%3D\&amp;reser ved $=0$. Accessed 12 Oct 2020.

41. European Food Safety Authority (EFSA) (2015) Final addendum to the Renewal Assessment Report - public version. Risk assessment provided by the rapporteur Member State Germany and co-rapporteur Member State Slovakia for the active substance GLYPHOSATE according to the procedure for the renewal of the inclusion of a second group of active substances. In laid down in Commission Regulation (EU) No. 1141/2010. October 2015. Available from: https://www.efsa.europa.eu/sites/default/ files/170922_glyphosate_statement.pdf. Accessed 28 Jan 2020.

42. European Food Safety Authority (EFSA) (2015) Conclusion on pesticide peer review-conclusion on the peer review of the pesticide risk assessment of the active substance glyphosate. EFSA J 13(11):4302. https://doi. org/10.2903/j.efsa.2015.4302

43. European Food Safety Authority (EFSA) (2018) Renewal assessment report-Public consultation on the active substance S-metolachlor - prepared by Rapporteur Member State: Germany; Co-Rapporteur Member State: France. https://www.efsa.europa.eu/de/consultations/call/1811291. Accessed 8 Feb 2021.

44. European Commission (2015) Volume 1—Pendimethalin—Rapporteur Member State (RMS): The Netherlands, Co-RMS: Spain. Draft Assessment Report and Proposed decision of the Netherlands prepared in the context of the possible renewal of the approval of pendimethalin under Regulation (EC) 1107/2009. https://www.efsa.europa.eu/en/consultati ons/call/150301. Accessed 8 Feb 2021.

45. European Food Safety Authority (EFSA) (2007) Draft Assessment Report (DAR) - public version - Initial risk assessment provided by the rapporteur Member State United Kingdom for the existing active substance TERBUTHYLAZINE of the third stage (part B) of the review programme referred to in Article 8(2) of Council Directive 91/414/EEC Volume 3, Annex B, part 4, B.8; November 2007. https://www.efsa.europa.eu/en/ consultations/call/public-consultation-active-substance-terbuthylazine0. Accessed 8 Feb 2021

46. European Food Safety Authority (EFSA) (2006). Draft Assessment Report (DAR) - public version - Initial risk assessment provided by the rapporteur Member State Sweden for the existing active substance PROSULFOCARB of the third stage (part A) of the review programme referred to in Article 8(2) of Council Directive 91/414/EEC. https://www.efsa.europa.eu/ en/consultations/call/public-consultation-active-substance-prosulfocarb. Accessed 8 Feb 2021.

\section{Publisher's Note}

Springer Nature remains neutral with regard to jurisdictional claims in published maps and institutional affiliations.

\section{Submit your manuscript to a SpringerOpen ${ }^{\circ}$ journal and benefit from:}

- Convenient online submission

- Rigorous peer review

- Open access: articles freely available online

- High visibility within the field

- Retaining the copyright to your article

Submit your next manuscript at $\boldsymbol{\nabla}$ springeropen.com 